Supplement of Atmos. Chem. Phys., 19, 8425-8470, 2019

https://doi.org/10.5194/acp-19-8425-2019-supplement

(C) Author(s) 2019. This work is distributed under

the Creative Commons Attribution 4.0 License.

(c) (i)

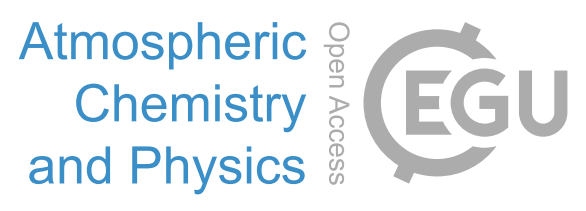

Supplement of

\title{
Land cover and its transformation in the backward trajectory footprint region of the Amazon Tall Tower Observatory
}

\section{Christopher Pöhlker et al.}

Correspondence to: Christopher Pöhlker (c.pohlker@mpic.de)

The copyright of individual parts of the supplement might differ from the CC BY 4.0 License. 
This file includes:

Supplementary information relating to methods and data analysis

Tables $\mathrm{S} 1$ to $\mathrm{S} 2$

Figs. S1 to S20

References 


\section{S1 Supplementary information relating to methods and data analysis}

\section{S1.1 List of GIS datasets used in this study}

In this study, the following GIS data sets were used:

(i) Landscape topography: Surface elevation data was obtained from the Shuttle Radar Topography Mission (SRTM) at 3 arc-seconds of spatial resolution (Farr et al., 2007). The data is assessable via the following link: https://www2.jpl.nasa.gov/srtm/southAmerica.htm (last access 02 Dec 2017).

(ii) Mean air temperature and annual precipitation: Mean air temperature and annual precipitation grid layers were obtained from the WorldClim database, version 1.4, at 10 arc-minute resolutions, available under www.worldclim.org (last access 27 Nov 2017) (Hijmans et al., 2005). The datasets were obtained by interpolation of the major long-term periods in climate databases (mostly for the 1950-2000 period), such as the Global Historical Climatology Network (GHCN), the Food and Agriculture Organization (FAO) of the United Nations, the World Meteorological Organization (WMO), the International Center for Tropical Agriculture (CIAT), R-HYdronet, among others. Spatial interpolation was done using the thin-plate smoothing spline algorithm (Hutchinson, 2004) and the 3 arc-seconds digital elevation model obtained from the SRTM and the ANUSPLIN software (see Hijmans et al., 2005 for further details).

(iii) Biomes and ecoregions: The biome and ecoregion classification in this study is based on the work by Olson et al. (2001). It is freely provided by the World Wildlife Fund (WWF) under https://www.worldwildlife.org/publications/terrestrial-ecoregions-of-the-world (last access 25 Feb 2018). This dataset specifies 867 different ecoregions worldwide in 14 different biomes (e.g., forest, grassland, desert, etc.).

(iv) Köppen-Geiger climate classification: The maps used in this study represent an update by Kottek et al. (2006) and Rubel and Kottek (2010) of the original classification maps. The data was obtained from http://koeppen-geiger.vu-wien.ac.at/shifts.htm (last access 25 Feb 2018).

(v) Human footprint and the last of the wild: The global maps on the human footprint index and areas with the "last of the wild" are based on the study by Sanderson et al. (2002). The areas with the "last of the wild" are characterized by the lowest human influences index and represent the "10\% wildest areas in each biome in each realm around the world" (Sanderson et al., 2002).

(vi) Potential vegetation: The potential vegetation coverage, which represents the land cover and natural vegetation in the absence of human alteration, was obtained from the International Satellite Land-Surface Climatology Project, Initiative II (ISLSCP II) data collection (Ramankutty and Foley, 2010). The data set is available online under http://daac.ornl.gov/ (last access $25 \mathrm{Feb}$ 2018).

(vii) Land cover: The land cover data in this study is based on the GlobCover 2009 data set, provided by the European space agency (ESA) and several partners (Arino et al., 2008). The data is freely 
available under http://due.esrin.esa.int/page_globcover.php (last access 25 Feb 2018). It provides 22 land cover classes, which are compatible with the UN land cover classification (UNLC). The spatial resolution of the GlobCover pixels equal $300 \mathrm{~m}$. The GlobCover 2009 data has been obtained in the period 1 Jan until 31 Dec 2009 (Congalton et al., 2014; Quaife and Cripps, 2016). An assessment of the geometric and thematic accuracy of the GlobCover 2009 data can be found in Defourny et al. (2009) documenting the generally high quality of the data. However, the authors also point out that the input data coverage for certain areas Amazonia is comparatively low, which increases the uncertainty and has to be considered carefully.

(viii) Normalized Difference Vegetation Index (NDVI): To obtain information on vegetation seasonality we used the NDVI data (Rouse et al., 1973), which is a widely implemented remote sensing vegetation index. It is directly related to the fraction of photosynthetically active radiation intercepted by vegetation and can be used as a proxy of net primary productivity (Paruelo et al., 2001). Mean monthly NDVI values and standard deviations of the different land cover classes within the $\mathrm{ROI}_{\text {foot }}$ were calculated from 16 composite MOD13Q1, obtained from Google Earth Engine for the period 2001-2016.

(ix) Forest cover and forest loss: The GIS data on forest cover and forest loss are based on work by Hansen et al. (2013). The data is freely provided by the University of Maryland (USA) under https://earthenginepartners.appspot.com/science-2013-global-forest (last access 25 Feb 2018). The forest cover data represent the status in the year 2000 and is provided as percent of forest cover per pixel. The spatial resolution equals $30 \mathrm{~m}$ per pixel. The forest loss data, which includes any tree cover loss in primary and secondary forests, is available within the time period 2001-2014 and refers to the status in the year 2000. In this study, we use both, forest loss data as total forest loss (integrated from 2001 to 2014) as well as annual forest loss (annually resolved for the years 2001 until 2014). Besides the widely used forest loss data provided by the University of Maryland, other forest loss data products, such as the Brazilian national satellitebased deforestation monitoring system (PRODES, www.obt.inpe.br/prodes, last access $25 \mathrm{Feb}$ 2017) as well as the studies by Souza et al. (2013) and Tyukavina et al. (2017), are available. Note that these different forest loss datasets agree on the overall trends, however, deviate to some extent in certain aspects, which can be explained by different methodological approaches (for details, see Tyukavina et al., 2017 and references therein). A limitation of the forest loss data used in this work is the fact that non-stand-replacement disturbances (i.e., selective logging, fire-related increases in forest vulnerability, etc.) are not included (Tyukavina et al., 2017).

(x) Fire maps: Two satellite-derived datasets on fire occurrence in the Amazon Basin were used in this study: First, fire-related carbon emission flux data based on Moderate Resolution Imaging Spectroradiometer (MODIS) observations has been obtained from the Global Fire Assimilation System (GFAS), available under http://eccharts.ecmwf.int/datasets/data/cams-gfas/ (last access 
$25 \mathrm{Feb} 2018$ ). This data is shown as average carbon emission flux data spanning from 20032017 in Fig. 15. Moreover, anomalies in carbon emission flux for individual years relative to the multi-year average (2003-2017) have been calculated (see Fig. S19). For details, refer to Kaiser et al. (2012). Second, data on detected fires based on multiple space-borne instruments (including MODIS) have been obtained from the Instituto Nacional de Pesquisas Espaciais (INPE), available under https://prodwww-queimadas.dgi.inpe.br/bdqueimadas (last access 25 Feb 2018). The INPE data has been downloaded for all available satellites, covering the entire continent and spanning the time period from Jan 2000 to Dec 2016. Note, the INPE data does not specify the fire intensity. It was used in this study to calculate a fire count per pixel as shown in Fig. S17. Multi-year average INPE and GFAS fire maps show similar geospatial distributions of fire occurrence and, thus, underline a good agreement of both data products.

(xi) Protected areas and conservations: The GIS data on conserved areas in the context of this study is based on the World Database on Protected Areas (WDPA), which has been created jointly by the International Union for Conservation of Nature (UICN), the United Nations Environment Program (UNEP), and partners (https://www.protectedplanet.net/, last access $25 \mathrm{Feb}$ 2018).

(xii) Land-based travel times to the nearest densely-populated area: This data is based on a study by Weiss et al., (2018) and constitutes the basis for the 'remoteness map' in Fig. 20b. The data has been obtained from Google Earth Engine under https://code.earthengine.google.com/ (last access 25 Feb 2018).

(xiii) Population density: The gridded population of the world data (version 4, GPWv4) has been compiled by the Center for International Earth Science Information Network (CIESIN), Columbia University, USA, and has been distributed by via the NASA SEDAC webpage (http://beta.sedac.ciesin.columbia.edu/data/set/gpw-v4-population-density-rev10, last access $25 \mathrm{Feb} 2018$ ). The data set used here, reflects the status in the year 2015. A detailed documentation can be found under http://dx.doi.org/10.7927/H4D50JX4 (last access 25 Feb 2018).

(xiv) Roads: The GIS information on highways and roads in the Amazon Basin were retrieved from the OpenStreetMap (OSM) data set, which is available via https://www.openstreetmap.org (last access 24 Feb 2018). The OSM data used here were released on 23 Feb 2018. The metadata specifies the type of roads. In the context of this study, we displayed primary, secondary, and tertiary roads as well as proposed new roads in the corresponding maps. We further used GIS data on the Amazonian road network from CRS maps, available under http://maps.csr.ufmg.br/ (last access $24 \mathrm{Feb} 2018$ ). The CRS data provided information on highway pavement status.

(xv) Power plants: The locations of thermoelectric power plots has been obtained from https://sigel.aneel.gov.br/Down/ (last access 25 Feb 2018).

(xvi) Reservoirs and dams: The global reservoir and dam dataset (GRanD) is based on a work by Lehner et al. (2011). The data has been obtained from the NASA SEDAC webpage 
http://sedac.ciesin.columbia.edu/data/set/grand-v1-dams-rev01, last access 25 Feb 2018).

(xvii) Mining: The GIS data on mining has been obtained from Sistema de Informações Geográficas da Mineração (SIGMINE) under http://sigmine.dnpm.gov.br/webmap/ (last access 04 Mar 2018). Note that this data is only available for Brazil.

(xviii) Shipping: Ship tracks in this study are represented by the geospatial information on shippingrelated $\mathrm{CO}_{2}$ emissions from the fossil fuel data assimilation system (FFDAS). The data is freely accessible under http://hpcg.purdue.edu/FFDAS/Map.php (last access 25 Feb 2018). Further information on the FFDAS data can be found in Rayner et al., (2010) and Asefi-Najafabady et al. (2014).

(xix) Deforestation scenarios: The deforestation scenarios used here are based on a modelling study on future deforestation patterns in the Amazon basin, spanning from 2002 to 2050. The study was conducted in the context of the large-scale biosphere-atmosphere experiment in the Amazon (LBA). The data has been compiled by Soares-Filho et al. (2013) and has been obtained from https://daac.ornl.gov/cgi-bin/dsviewer.pl?ds_id=1153 (last access 25 Feb 2018). It is available as "governance" and "business as usual (BAU)" scenarios. Further information can be found in Soares-Filho et al. (2006). 
Table S1. The land cover contributions according the GlobCover 2009 data, resolved by BT clusters and weighted by air mass residence time. The data summarized here is plotted in Fig. 11.

\begin{tabular}{|c|c|c|c|c|c|c|c|c|c|c|c|c|c|c|c|c|c|c|c|c|}
\hline \multirow{2}{*}{ GlobCover categories } & \multicolumn{4}{|c|}{$\mathbf{N E}$} & \multicolumn{5}{|c|}{ ENE } & \multicolumn{5}{|c|}{$\mathbf{E}$} & \multicolumn{4}{|c|}{ ESE } & \multirow[t]{2}{*}{ SW1 } & \multirow{2}{*}{$\begin{array}{l}\text { Av } \\
\text { all }\end{array}$} \\
\hline & NE1 & NE2 & NE3 & Av & ENE & ENE & ENE & ENE & Av & E1 & E2 & E3 & E4 & Av & ESE1 & ESE2 & ESE3 & Av & & \\
\hline 11 & 0 & 0 & 0 & $\mathbf{0}$ & 0 & 0 & 0 & 0 & $\mathbf{0}$ & 0 & 0 & 0 & 0 & $\mathbf{0}$ & 0 & 0 & 0 & $\mathbf{0}$ & 0 & $\mathbf{0}$ \\
\hline 14 & 0.001 & 0.001 & 0.002 & 0.001 & 0.001 & 0.009 & 0.007 & 0.005 & 0.006 & 0.017 & 0.143 & 0.226 & 0.524 & 0.228 & 1.177 & 3.419 & 3.370 & 2.655 & 0.035 & 0.596 \\
\hline 20 & 0.250 & 0.164 & 0.150 & 0.188 & 0.730 & 0.895 & 0.727 & 0.502 & 0.714 & 1.910 & 2.983 & 2.117 & 2.055 & 2.266 & 3.143 & 6.593 & 9.084 & 6.273 & 0.850 & 2.144 \\
\hline 30 & 0.185 & 0.121 & 0.095 & 0.134 & 0.340 & 0.294 & 0.229 & 0.153 & 0.254 & 0.900 & 1.689 & 1.684 & 1.988 & 1.565 & 1.340 & 4.484 & 8.006 & 4.610 & 0.306 & 1.454 \\
\hline 40 & 74.79 & 47.95 & 37.95 & 53.56 & 86.11 & 54.88 & 43.16 & 34.20 & 54.59 & 65.75 & 49.53 & 38.42 & 32.84 & 46.64 & 83.16 & 68.48 & 55.79 & 69.14 & 84.84 & 57.19 \\
\hline 50 & 0.001 & 0.001 & 0.002 & 0.001 & 0.001 & 0.005 & 0.003 & 0.003 & 0.003 & 0.003 & 0.092 & 0.045 & 0.054 & 0.049 & 0.562 & 0.942 & 1.183 & 0.896 & 0.011 & 0.194 \\
\hline 60 & 0 & 0 & 0 & $\mathbf{0}$ & 0 & 0 & 0 & 0 & $\mathbf{0}$ & 0.001 & 0.030 & 0.091 & 0.104 & 0.057 & 0.022 & 0.428 & 0.766 & 0.405 & 0 & 0.096 \\
\hline 70 & 0 & 0 & 0 & 0 & 0 & 0 & 0 & 0 & 0 & 0 & 0 & 0 & 0 & 0 & 0 & 0 & 0 & 0 & 0 & 0 \\
\hline 90 & 0 & 0 & 0 & 0 & 0 & 0 & 0 & 0 & 0 & 0 & 0 & 0 & 0 & 0 & 0 & 0 & 0 & 0 & 0 & 0 \\
\hline 100 & 0 & 0 & 0 & 0 & 0 & 0 & 0 & 0 & $\mathbf{0}$ & 0 & 0 & 0 & 0 & o & 0 & 0 & 0 & 0 & 0 & o \\
\hline 110 & 0.051 & 0.039 & 0.042 & 0.044 & 0.206 & 0.219 & 0.152 & 0.102 & 0.170 & 0.551 & 0.525 & 0.500 & 0.516 & 0.523 & 0.113 & 0.274 & 0.726 & 0.371 & 0.094 & 0.274 \\
\hline 120 & 0 & 0 & 0 & 0 & 0.002 & 0.008 & 0.007 & 0.004 & 0.005 & 0.006 & 0.008 & 0.015 & 0.018 & 0.012 & 0.002 & 0.007 & 0.035 & 0.015 & 0.017 & 0.009 \\
\hline 140 & 0.202 & 0.145 & 0.119 & 0.155 & 0.498 & 0.287 & 0.190 & 0.130 & 0.276 & 0.655 & 0.481 & 0.303 & 0.217 & 0.414 & 0.337 & 0.423 & 0.343 & 0.368 & 0.558 & 0.326 \\
\hline 150 & 0 & 0 & 0 & 0 & 0 & 0 & 0 & 0 & 0 & 0 & 0.015 & 0.020 & 0.021 & 0.014 & 0.001 & 0.005 & 0.016 & 0.007 & 0 & 0.005 \\
\hline 160 & 1.259 & 0.843 & 0.662 & 0.921 & 2.267 & 2.413 & 1.944 & 1.335 & 1.990 & 7.317 & 7.259 & 5.107 & 4.121 & 5.951 & 2.049 & 2.126 & 2.201 & 2.125 & 4.653 & 3.037 \\
\hline 170 & 0.007 & 0.007 & 0.005 & 0.006 & 0.001 & 0.005 & 0.004 & 0.003 & 0.003 & 0.029 & 0.426 & 0.287 & 0.224 & 0.242 & 0 & 0.044 & 0.118 & 0.054 & 0 & 0.077 \\
\hline 180 & 0.922 & 0.626 & 0.488 & 0.679 & 2.781 & 1.202 & 0.812 & 0.540 & 1.334 & 3.520 & 2.562 & 1.450 & 1.029 & 2.140 & 2.476 & 2.629 & 2.108 & 2.404 & 3.005 & 1.743 \\
\hline 190 & 0.001 & 0.001 & 0 & 0.001 & 0.006 & 0.006 & 0.003 & 0.003 & 0.005 & 0.015 & 0.018 & 0.018 & 0.021 & 0.018 & 0.001 & 0.006 & 0.012 & 0.006 & 0.055 & 0.011 \\
\hline 200 & 0 & 0 & 0 & 0 & 0.017 & 0.003 & 0.001 & 0 & 0.005 & 0.019 & 0.062 & 0.095 & 0.092 & 0.067 & 0.012 & 0.023 & 0.048 & 0.028 & 0.009 & 0.025 \\
\hline 210 & 20.55 & 48.92 & 59.52 & 43.00 & 5.034 & 38.29 & 51.67 & 62.25 & 39.31 & 16.39 & 30.26 & 46.38 & 53.13 & 36.54 & 3.981 & 4.978 & 4.817 & 4.592 & 4.621 & 30.05 \\
\hline 220 & 0 & 0 & 0 & 0 & 0 & 0 & 0 & 0 & 0 & 0 & 0.002 & 0.001 & 0.001 & 0.001 & 0 & 0.001 & 0.001 & 0.001 & 0 & 0 \\
\hline 230 & 0 & 0 & 0 & 0 & 0 & 0 & 0 & 0 & 0 & 0 & 0 & 0 & 0 & 0 & 0 & 0 & 0 & 0 & 0 & 0 \\
\hline
\end{tabular}


Table S2. Weighted quantification of forest cover and forest loss within the footprints of the 15 back trajectory clusters as specified in Fig. 13. The data summarized in this table is visualized in Fig. S15.

\begin{tabular}{|c|c|c|c|c|c|c|c|c|c|c|c|c|c|c|c|c|}
\hline & & \multicolumn{15}{|c|}{ Clusters } \\
\hline & & NE1 & NE2 & NE3 & ENE1 & ENE2 & ENE3 & ENE4 & E1 & E2 & E3 & E4 & ESE1 & ESE2 & ESE3 & SW1 \\
\hline \multirow{2}{*}{2000} & Tree cover [\%] & 77.16 & 49.447 & 39.142 & 88.77 & 56.673 & 44.567 & 35.228 & 71.768 & 56.929 & 43.676 & 37.36 & 86.07 & 74.06 & 63.592 & 90.187 \\
\hline & Forest loss [\%] & -- & -- & -- & -- & -- & -- & -- & -- & -- & -- & -- & -- & -- & -- & -- \\
\hline \multirow{2}{*}{2001} & Tree cover [\%] & 77.151 & 49.439 & 39.136 & 88.641 & 56.602 & 44.521 & 35.204 & 71.495 & 56.662 & 43.527 & 37.24 & 85.58 & 73.521 & 63.172 & 90.046 \\
\hline & Forest loss $[\%]$ & 0.015 & 0.017 & 0.015 & 0.154 & 0.124 & 0.104 & 0.069 & 0.381 & 0.468 & 0.341 & 0.321 & 0.572 & 0.727 & 0.66 & 0.156 \\
\hline \multirow{2}{*}{2002} & Tree cover $[\%]$ & 77.139 & 49.431 & 39.13 & 88.483 & 56.526 & 44.472 & 35.178 & 71.217 & 56.376 & 43.365 & 37.108 & 85.085 & 72.84 & 62.596 & 89.828 \\
\hline & Forest loss [\%] & 0.015 & 0.016 & 0.015 & 0.178 & 0.134 & 0.111 & 0.073 & 0.386 & 0.5 & 0.369 & 0.351 & 0.572 & 0.912 & 0.9 & 0.241 \\
\hline \multirow{2}{*}{2003} & Tree cover [\%] & 77.131 & 49.426 & 39.127 & 88.38 & 56.472 & 44.437 & 35.161 & 71.017 & 56.171 & 43.245 & 37.012 & 84.707 & 72.368 & 62.213 & 89.703 \\
\hline & Forest loss [\%] & 0.01 & 0.01 & 0.008 & 0.116 & 0.096 & 0.078 & 0.049 & 0.277 & 0.357 & 0.273 & 0.255 & 0.434 & 0.627 & 0.593 & 0.139 \\
\hline \multirow{2}{*}{2004} & Tree cover $[\%]$ & 77.116 & 49.416 & 39.12 & 88.209 & 56.377 & 44.375 & 35.13 & 70.664 & 55.861 & 43.064 & 36.866 & 84.012 & 71.51 & 61.501 & 89.521 \\
\hline & Forest loss [\%] & 0.02 & 0.021 & 0.018 & 0.192 & 0.166 & 0.14 & 0.089 & 0.487 & 0.537 & 0.41 & 0.388 & 0.795 & 1.132 & 1.095 & 0.2 \\
\hline \multirow{2}{*}{2005} & Tree cover $[\%]$ & 77.106 & 49.409 & 39.115 & 88.097 & 56.315 & 44.334 & 35.108 & 70.414 & 55.611 & 42.932 & 36.753 & 83.381 & 70.533 & 60.767 & 89.306 \\
\hline & Forest loss [\%] & 0.013 & 0.014 & 0.013 & 0.125 & 0.109 & 0.092 & 0.064 & 0.342 & 0.43 & 0.297 & 0.297 & 0.716 & 1.274 & 1.117 & 0.237 \\
\hline \multirow{2}{*}{2006} & Tree cover $[\%]$ & 77.094 & 49.401 & 39.11 & 87.951 & 56.238 & 44.283 & 35.082 & 70.154 & 55.331 & 42.774 & 36.622 & 82.869 & 69.736 & 60.099 & 89.085 \\
\hline & Forest loss [\%] & 0.015 & 0.016 & 0.014 & 0.163 & 0.135 & 0.113 & 0.072 & 0.356 & 0.481 & 0.356 & 0.345 & 0.576 & 1.025 & 1.003 & 0.242 \\
\hline \multirow{2}{*}{2007} & Tree cover $[\%]$ & 77.083 & 49.393 & 39.105 & 87.823 & 56.178 & 44.245 & 35.063 & 69.896 & 55.048 & 42.626 & 36.499 & 82.407 & 69.085 & 59.531 & 88.965 \\
\hline & Forest loss [\%] & 0.015 & 0.016 & 0.014 & 0.143 & 0.105 & 0.085 & 0.054 & 0.352 & 0.483 & 0.332 & 0.323 & 0.516 & 0.828 & 0.844 & 0.131 \\
\hline \multirow{2}{*}{2008} & Tree cover $[\%]$ & 77.067 & 49.382 & 39.098 & 87.695 & 56.109 & 44.2 & 35.039 & 69.633 & 54.79 & 42.479 & 36.376 & 81.818 & 68.288 & 58.862 & 88.842 \\
\hline & Forest loss [\%] & 0.021 & 0.022 & 0.017 & 0.143 & 0.12 & 0.1 & 0.067 & 0.357 & 0.438 & 0.33 & 0.321 & 0.655 & 1.003 & 0.984 & 0.135 \\
\hline \multirow{2}{*}{2009} & Tree cover $[\%]$ & 77.046 & 49.368 & 39.089 & 87.403 & 55.963 & 44.104 & 34.989 & 69.165 & 54.378 & 42.219 & 36.176 & 81.272 & 67.607 & 58.305 & 88.61 \\
\hline & Forest loss [\%] & 0.027 & 0.028 & 0.024 & 0.324 & 0.255 & 0.213 & 0.142 & 0.633 & 0.696 & 0.578 & 0.52 & 0.603 & 0.848 & 0.81 & 0.253 \\
\hline \multirow{2}{*}{2010} & Tree cover [\%] & 77.031 & 49.358 & 39.082 & 87.314 & 55.916 & 44.071 & 34.969 & 68.962 & 54.083 & 42.057 & 36.031 & 80.871 & 66.916 & 57.67 & 88.344 \\
\hline & Forest loss [\%] & 0.02 & 0.021 & 0.018 & 0.099 & 0.083 & 0.074 & 0.056 & 0.273 & 0.495 & 0.359 & 0.376 & 0.44 & 0.852 & 0.916 & 0.29 \\
\hline \multirow{2}{*}{2011} & Tree cover [\%] & 77.02 & 49.351 & 39.077 & 87.236 & 55.865 & 44.035 & 34.949 & 68.789 & 53.908 & 41.956 & 35.943 & 80.479 & 66.385 & 57.237 & 88.232 \\
\hline & Forest loss [\%] & 0.014 & 0.014 & 0.012 & 0.087 & 0.09 & 0.079 & 0.057 & 0.231 & 0.293 & 0.222 & 0.228 & 0.428 & 0.648 & 0.617 & 0.122 \\
\hline \multirow{2}{*}{2012} & Tree cover [\%] & 76.982 & 49.326 & 39.06 & 87.058 & 55.77 & 43.969 & 34.911 & 68.488 & 53.649 & 41.796 & 35.808 & 79.88 & 65.559 & 56.494 & 87.997 \\
\hline & Forest loss [\%] & 0.049 & 0.05 & 0.044 & 0.197 & 0.165 & 0.146 & 0.107 & 0.401 & 0.431 & 0.351 & 0.347 & 0.651 & 0.999 & 1.052 & 0.255 \\
\hline \multirow{2}{*}{2013} & Tree cover $[\%]$ & 76.962 & 49.313 & 39.051 & 86.916 & 55.698 & 43.92 & 34.884 & 68.207 & 53.302 & 41.604 & 35.646 & 79.524 & 64.882 & 55.808 & 87.834 \\
\hline & Forest loss [\%] & 0.026 & 0.026 & 0.024 & 0.157 & 0.125 & 0.108 & 0.077 & 0.373 & 0.575 & 0.42 & 0.414 & 0.384 & 0.809 & 0.959 & 0.177 \\
\hline \multirow{2}{*}{2014} & Tree cover [\%] & 76.942 & 49.301 & 39.043 & 86.758 & 55.613 & 43.863 & 34.854 & 67.902 & 52.976 & 41.411 & 35.49 & 79.052 & 64.125 & 55.087 & 87.668 \\
\hline & Forest loss [\%] & 0.026 & 0.024 & 0.02 & 0.175 & 0.147 & 0.125 & 0.086 & 0.404 & 0.537 & 0.421 & 0.398 & 0.506 & 0.896 & 0.995 & 0.179 \\
\hline
\end{tabular}




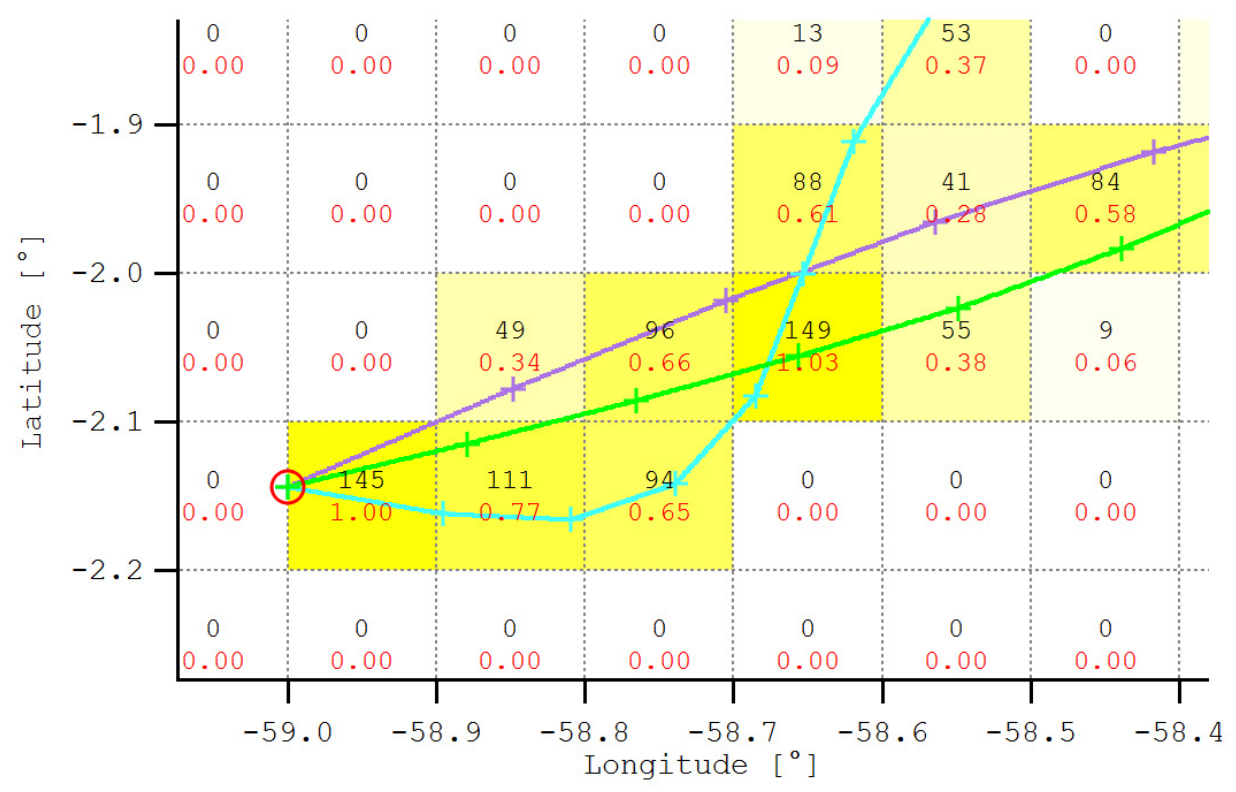

Figure S1. Sketch illustrating the weighting of the trajectory points, in this example for 3 trajectories (purple, green, cyan) starting at ATTO (red circle). The original trajectory points (crosses, time step 1 hour) are interpolated in order to get points on a 1-minute basis. Due to the interpolation of the hourly HYSPLIT output, the procedure weighted the individual trajectory points by residence time. The interpolated points are counted within a $0.1^{\circ}$ by $0.1^{\circ}$ grid (black numbers), e.g., 145 points within the grid besides ATTO. The absolute numbers are not very meaningful. For example, the numbers would be doubled in case of interpolating the trajectories to 0.5 -minute steps instead on 1-minute steps, and they would be quadrupled in case of choosing a $2^{\circ}$ by $2^{\circ}$ grid for counting. To avoid this scaling issue, the absolute counts were divided by the counts in the grid pixel beside the ATTO site location (red numbers). These quotients we refer to as 'relative trajectory densities' and the resulting maps have been called 'air mass residence time maps'. Slightly modified, this procedure can also be used to obtain averaged trajectory heights as well as average rainfall, mixing depth, etc. 


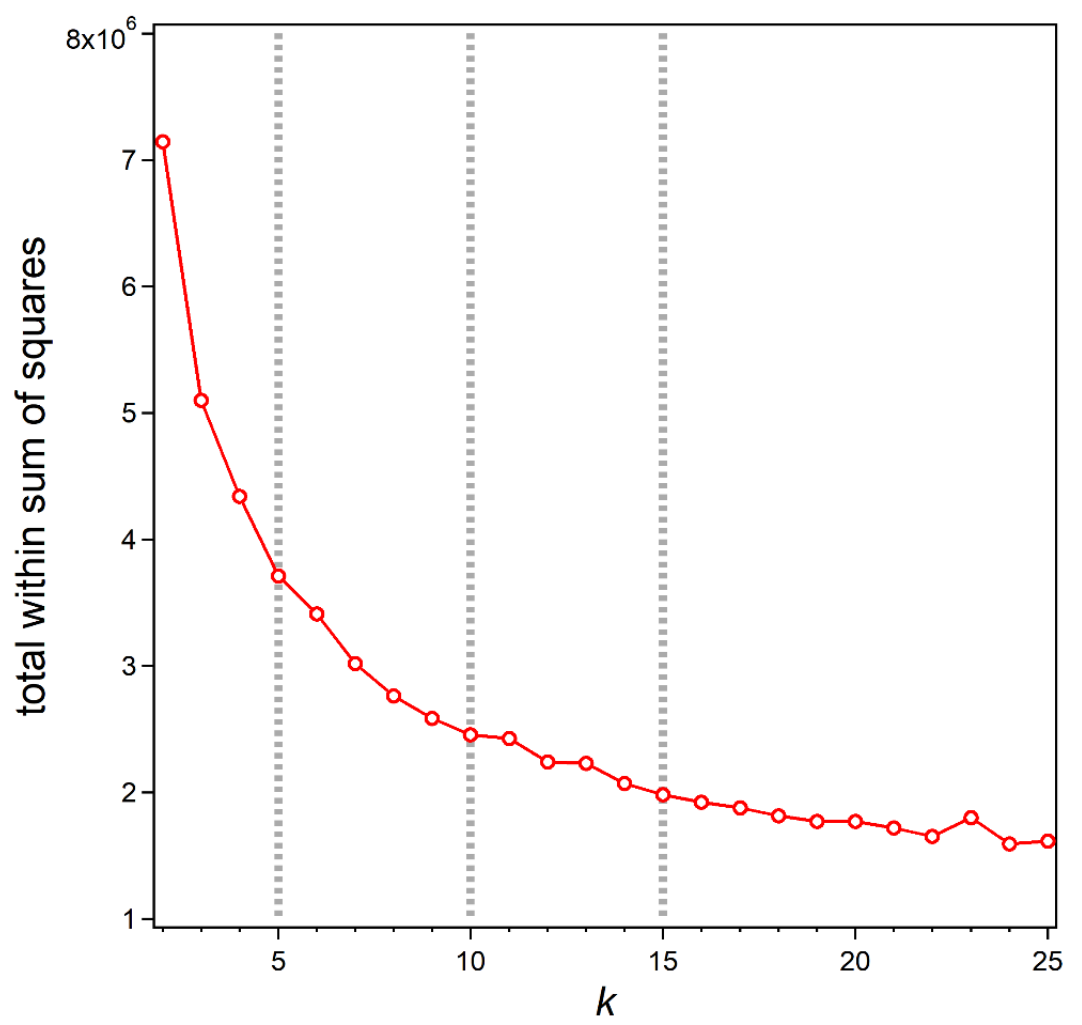

Figure S2. Total within-cluster sum of squares of $k$-means cluster analysis (CA) as a function of the pre-defined number of clusters, $k$. The 'elbow', which is not particularly pronounced here, is located in the range between $k=5$ and $k=10$. A comparison of $k$-means CA results for $k=5,10$, and 15 is shown in Fig. S3. For the systematic $k$-means CA in this study, $k=15$, which is located after the elbow is reached, has been chosen for reasons outlined in Sect. 2.4. 

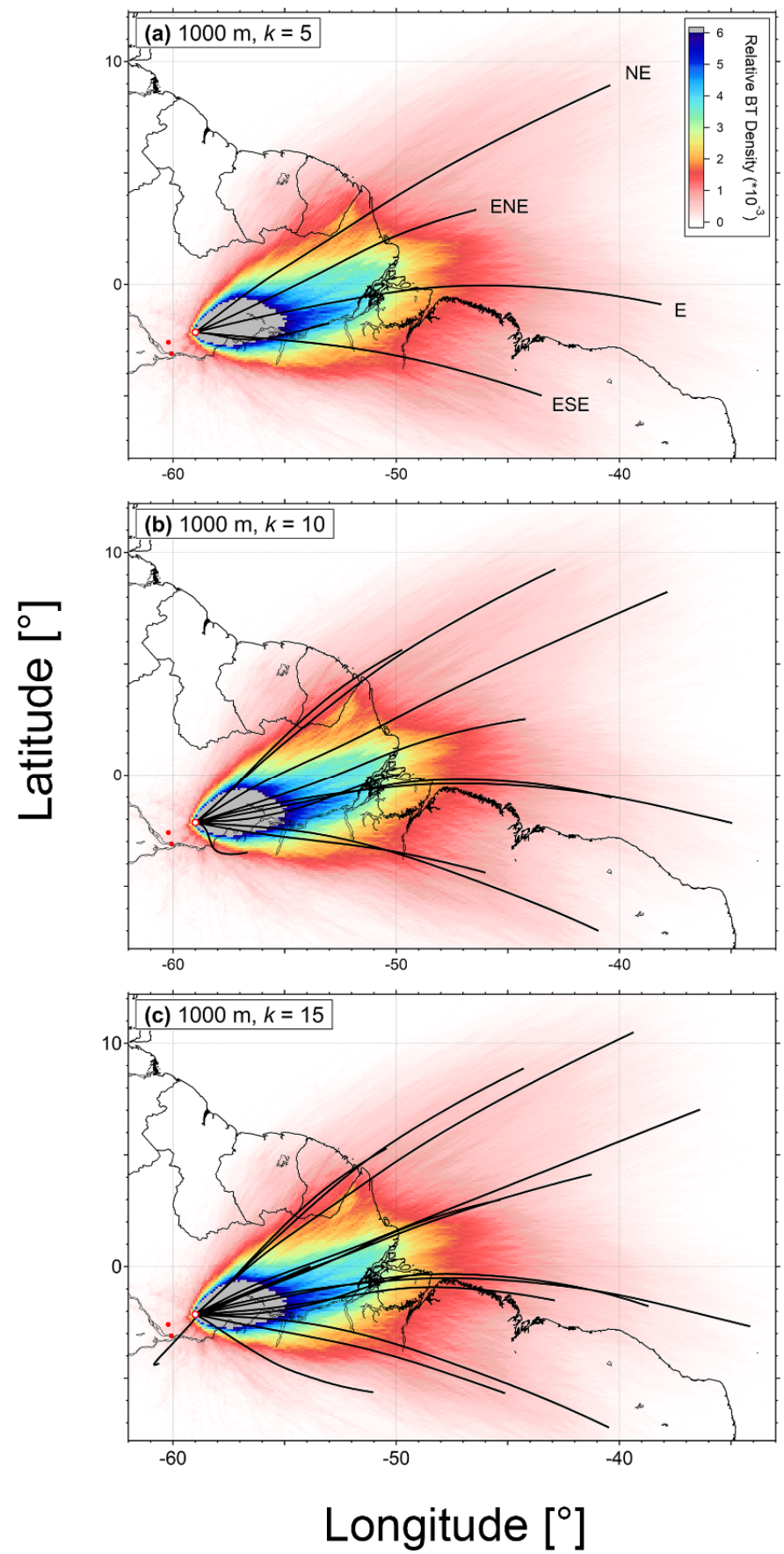

Figure S3. Air mass residence time maps, based on the entire ensembles of 3-day BTs (starting height 1000 m AGL, 01 Jan 2008 - 30 Jun 2016) with results from three $k$-means CA runs for $k=5, k=10$, and $k=15$ (compare Fig. S2). 


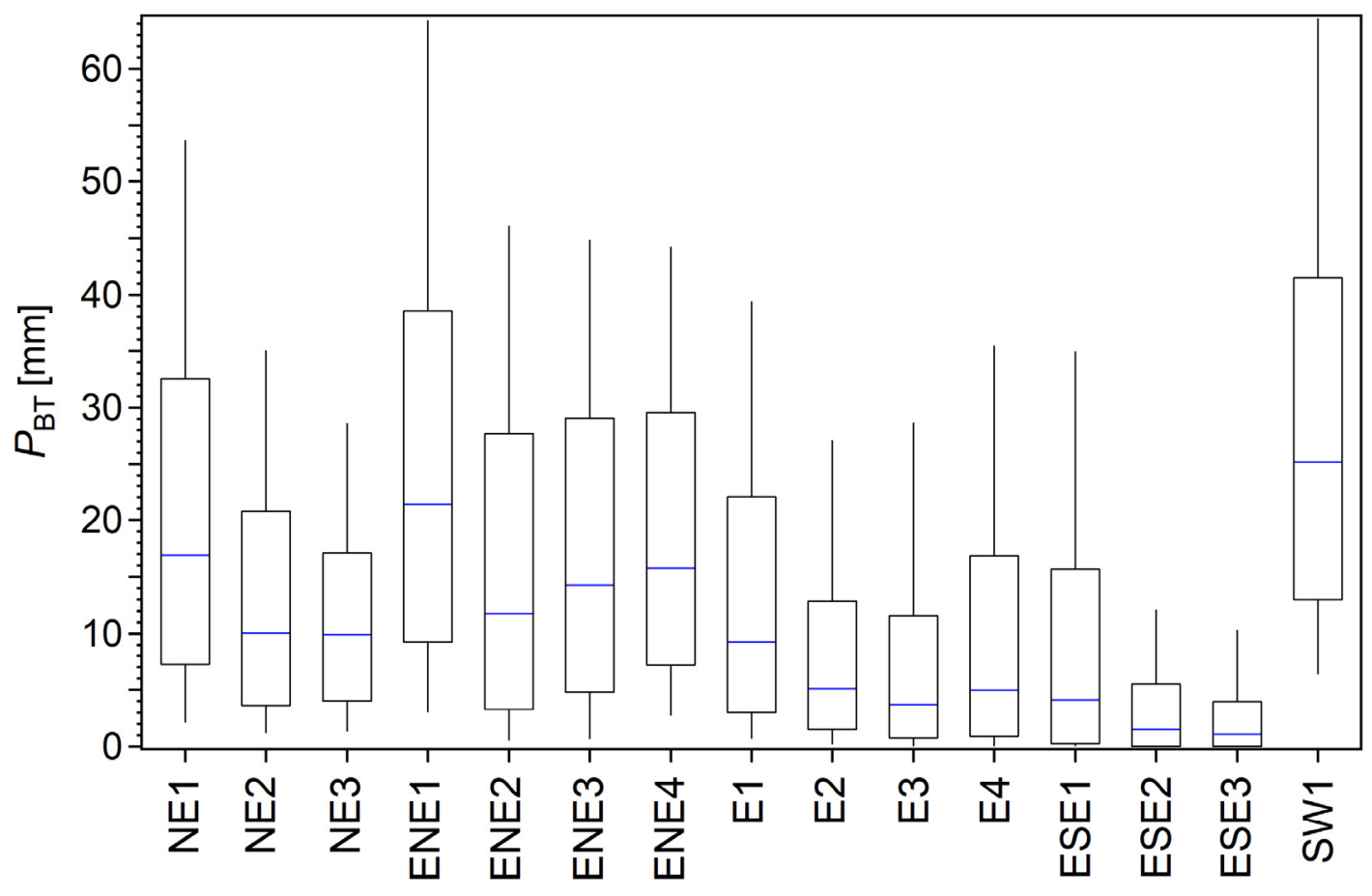

Figure S4. Statistical distribution (box and whisker plots) of cumulative precipitation, $P_{\mathrm{BT}}$, for entire set of 744963 -day BTs, sorted by clusters. Results are based on $k=15$ case (compare Fig. S2 and S3). Horizontal blue line represents median; lower and upper borders of box represents 25 and 75 percentiles. Whiskers represent 10 and 90 percentiles. Distributions show clearly enhanced $P_{\mathrm{BT}}$ for slow BT wind speed regimes (i.e., NE1, ENE1, E1, ESE1) in comparison to fast BT wind speed regimes (e.g., NE3, ENE3, E4, ESE3). 

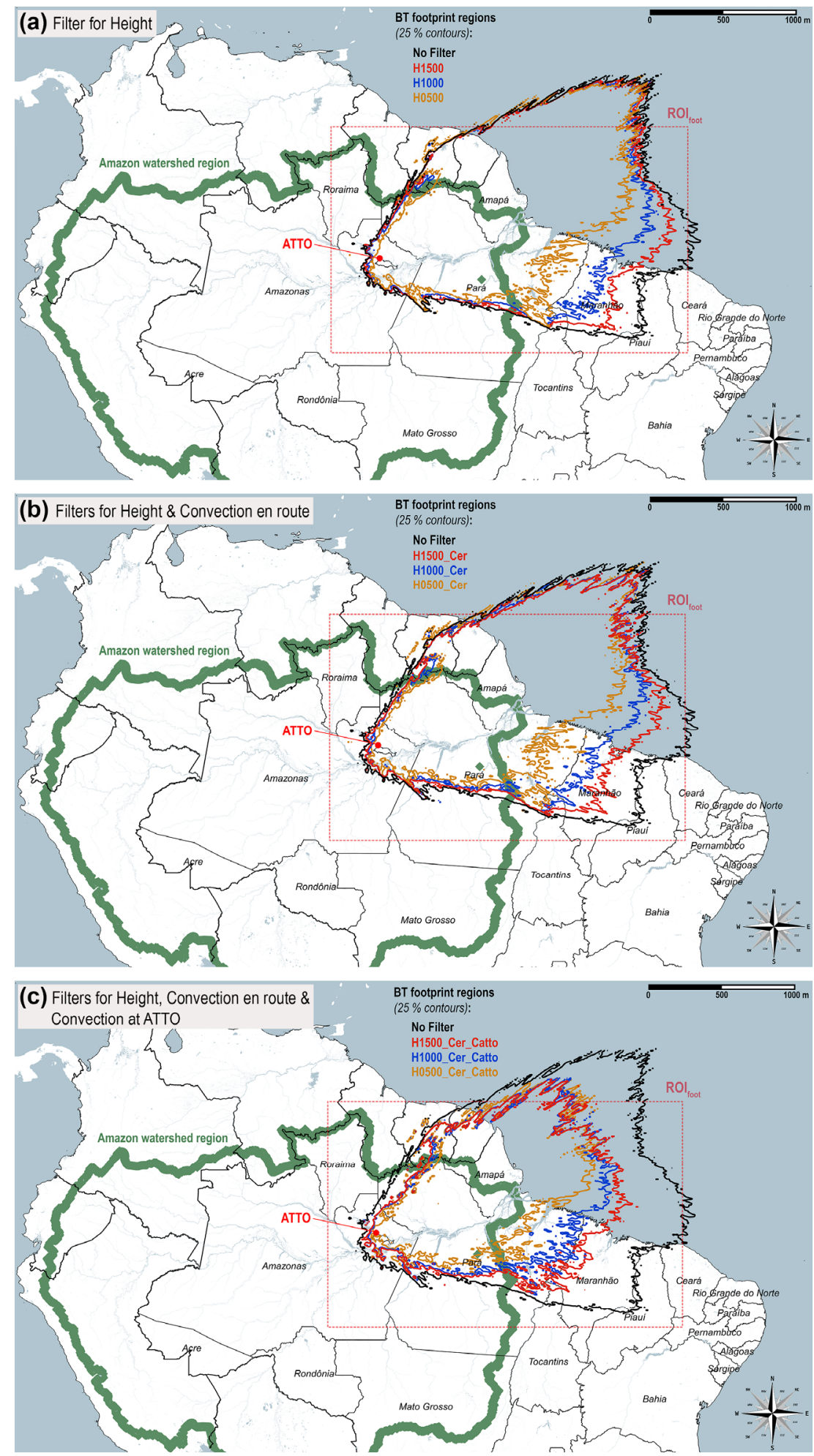

Figure S5. Versions of ATTO BT footprint region based on differently filtered BT ensembles as specified in Table 1 and discussed in Sect. 2.5 and 3.3. 


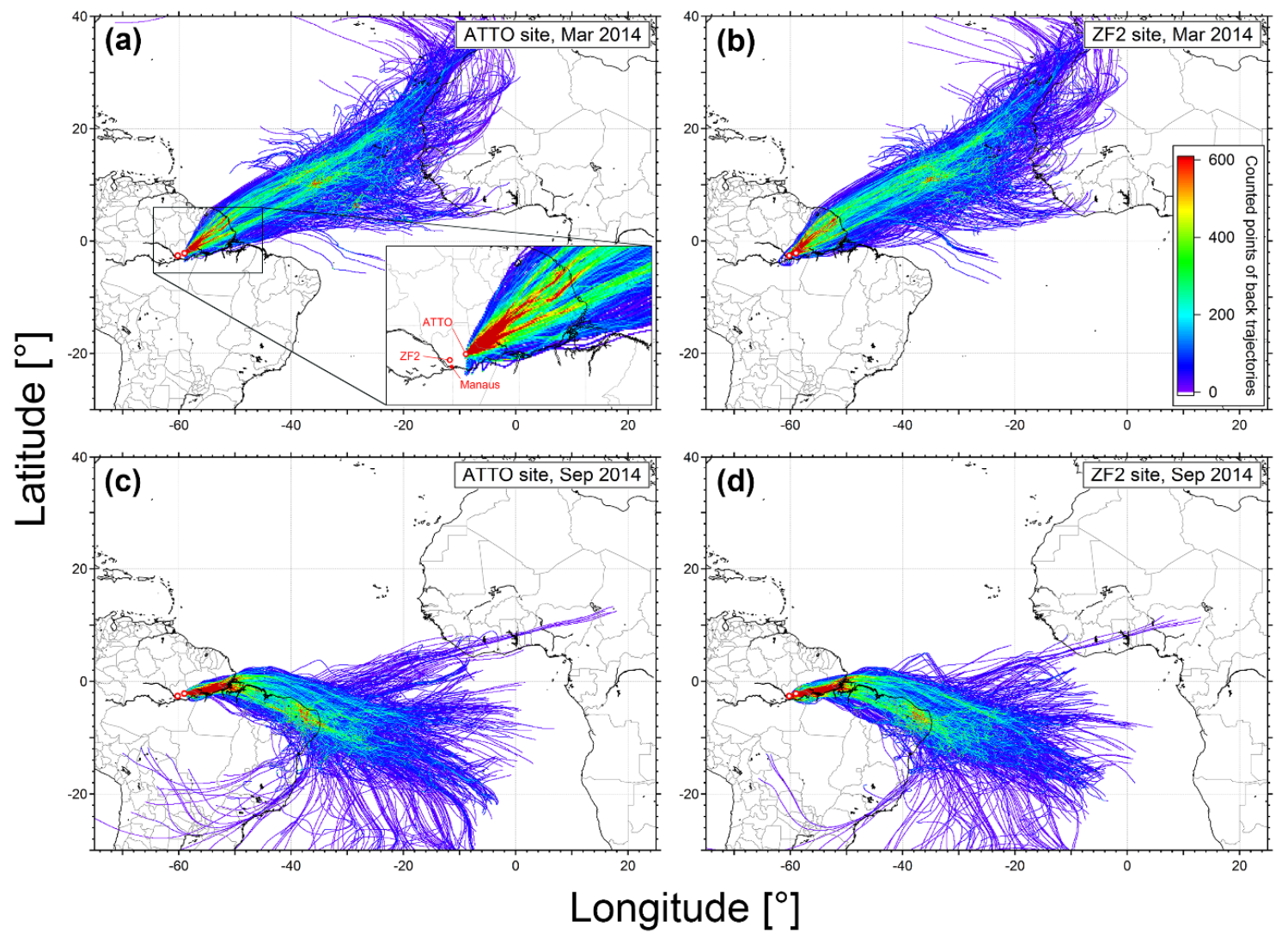

Figure S6. Comparison of 9-day HYSPLIT back trajectory (BT) ensembles for a selected wet season month (Mar 2014) and a selected dry season month (Sep 2014), underlining that large scale circulation patterns towards the Amazonian ATTO and ZF2 sites typically are very similar. Settings for BT calculations at both sites were identical (GDAS1, start height $1000 \mathrm{~m}$ AGL, trajectories started every $1 \mathrm{~h}$ ). In this context, compare also Saturno et al. (2017). 


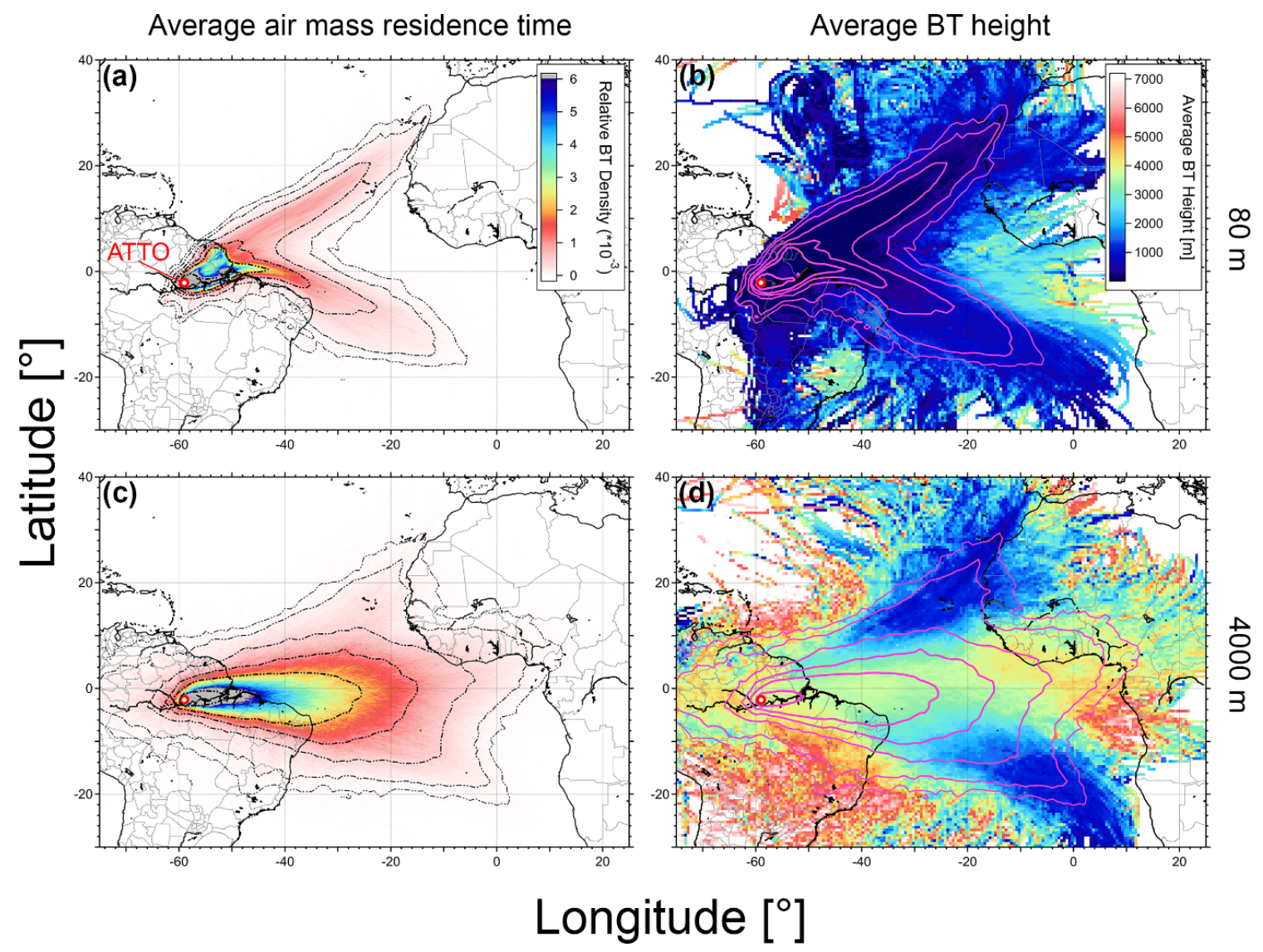

Figure S7. HYSPLIT back trajectory (BT) ensembles showing the large scale trade wind circulation in the Atlantic region and the seasonal oscillation between Northern and Southern hemispheric influence at ATTO by mean of air mass residence time maps (a and $\mathbf{c}$ ) and average BT height maps (b and $\mathbf{d})$. The BT ensembles comprise all 74496 individual 9-day BTs, spanning a multi-year time period from 01 Jan 2008 until 30 June 2016. The BT analysis shown here was conducted for the start heights $80 \mathrm{~m}$ and $4000 \mathrm{~m}$ AGL. The contour lines in $\mathbf{b}$ and $\mathbf{d}$ were adopted from $\mathbf{a}$ and $\mathbf{c}$ to visualize the patterns in relative BT density on top of the average BT height map. Corresponding data for the BT start heights $200 \mathrm{~m}, 1000 \mathrm{~m}$, and $2000 \mathrm{~m}$ can be found in Fig. 2. 


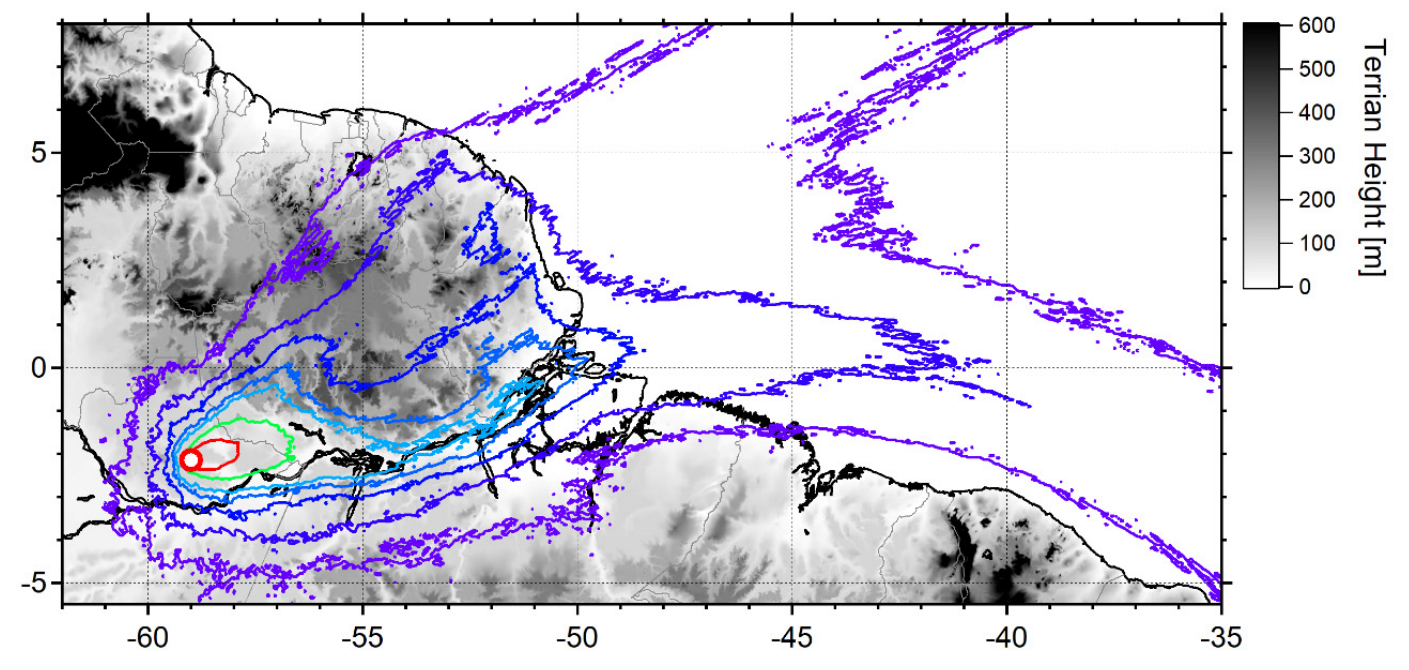

Figure S8. HYSPLIT back trajectory (BT) ensemble at start height of $200 \mathrm{~m}$ suggesting topography influence along the Amazon River valley. 

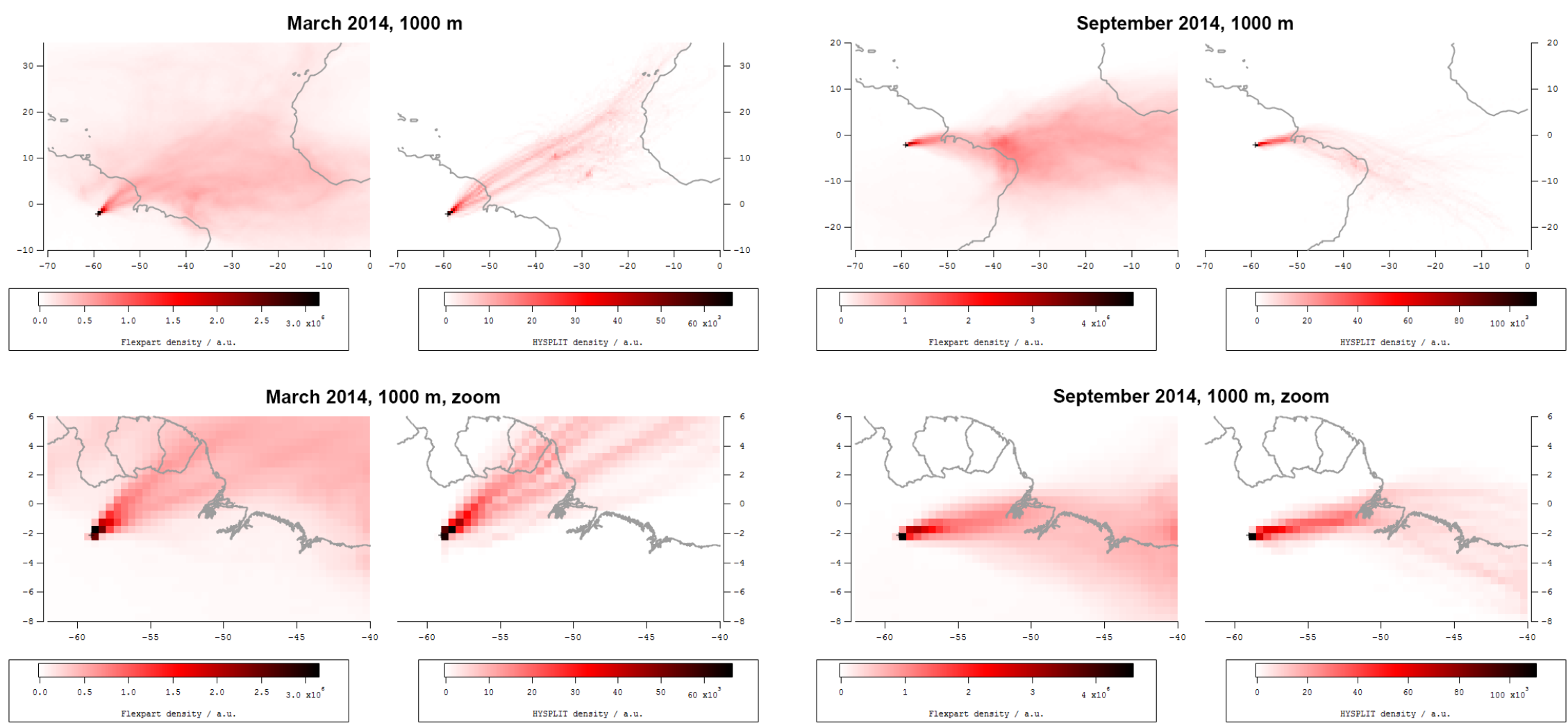

Figure S9. Alternative representation of FLEXPART and HYSPLIT back trajectory ensembles for wet season (Mar 2014, left) and dry season (Sep 2014, right) case studies as shown in Fig. 3. The color code represents relative BT density maps for both model. Top row shows results on a large-scale map (including NE South American and Western Africa). Bottom row shows same results as a zoomed map covering the NE Amazon Basin. 

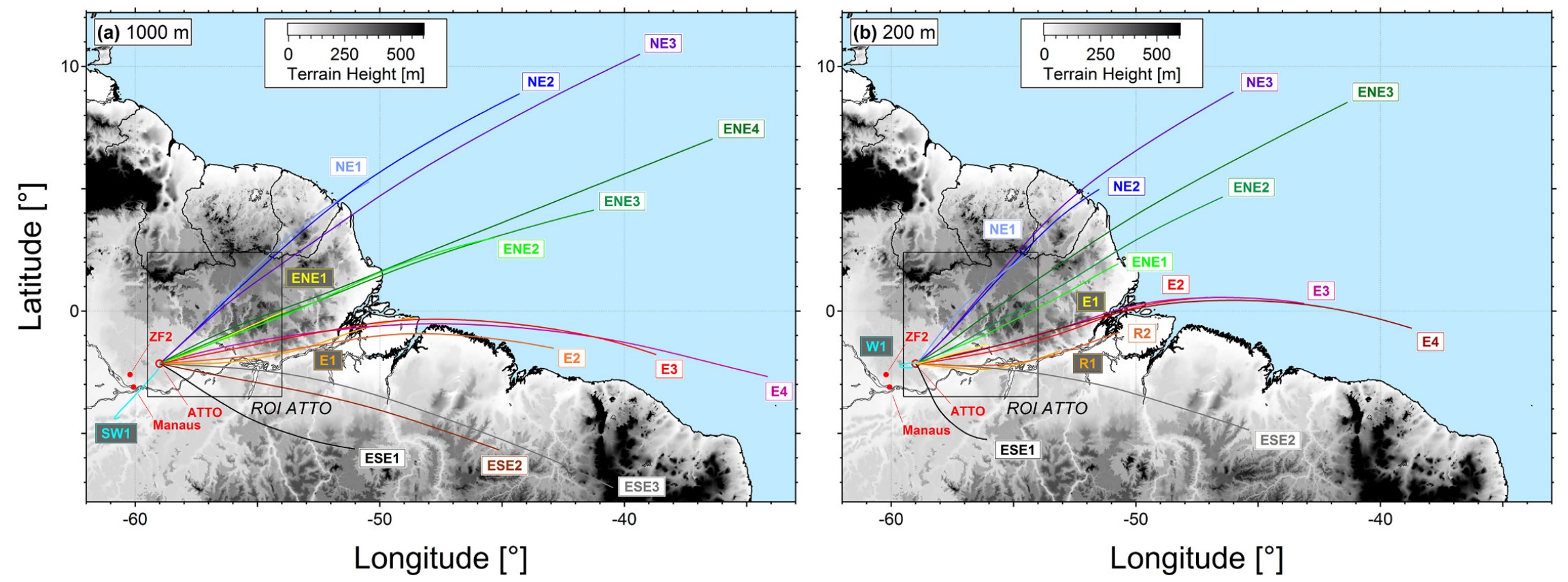

Figure S10. Map of northeast Amazon Basin with 15 clusters from systematic $k$-means back trajectory (BT) cluster analysis based on entire HYSPLIT data set (3-day BTs, 1 Jan 2008 - 30 Jun 2016). Here, the result from two different trajectory start heights are compared: $1000 \mathrm{~m}$ in (a) and $200 \mathrm{~m}$ AGL in (b). Throughout this study, the BT data set at $1000 \mathrm{~m}$ AGL is subject of a detailed analysis. The $1000 \mathrm{~m}$ case in (a) is identical to Fig. 4 and has been added here to allow a direct comparison. For the $200 \mathrm{~m}$ case, the cluster analysis has partitioned the individual BTs into four subcategories: (i) three NE clusters (i.e., NE1, NE2, NE3), (ii) three ENE clusters (i.e., ENE1, ENE2, ENE3), (iii) six easterly clusters (i.e., E1, E2, E3, E4) including two 'river trajectories' R1 and R2, and (iv) three inland trajectories (i.e., ESE1, ES2, W1). A topographic map is represented by a grey scale, which is capped at $600 \mathrm{~m}$. 

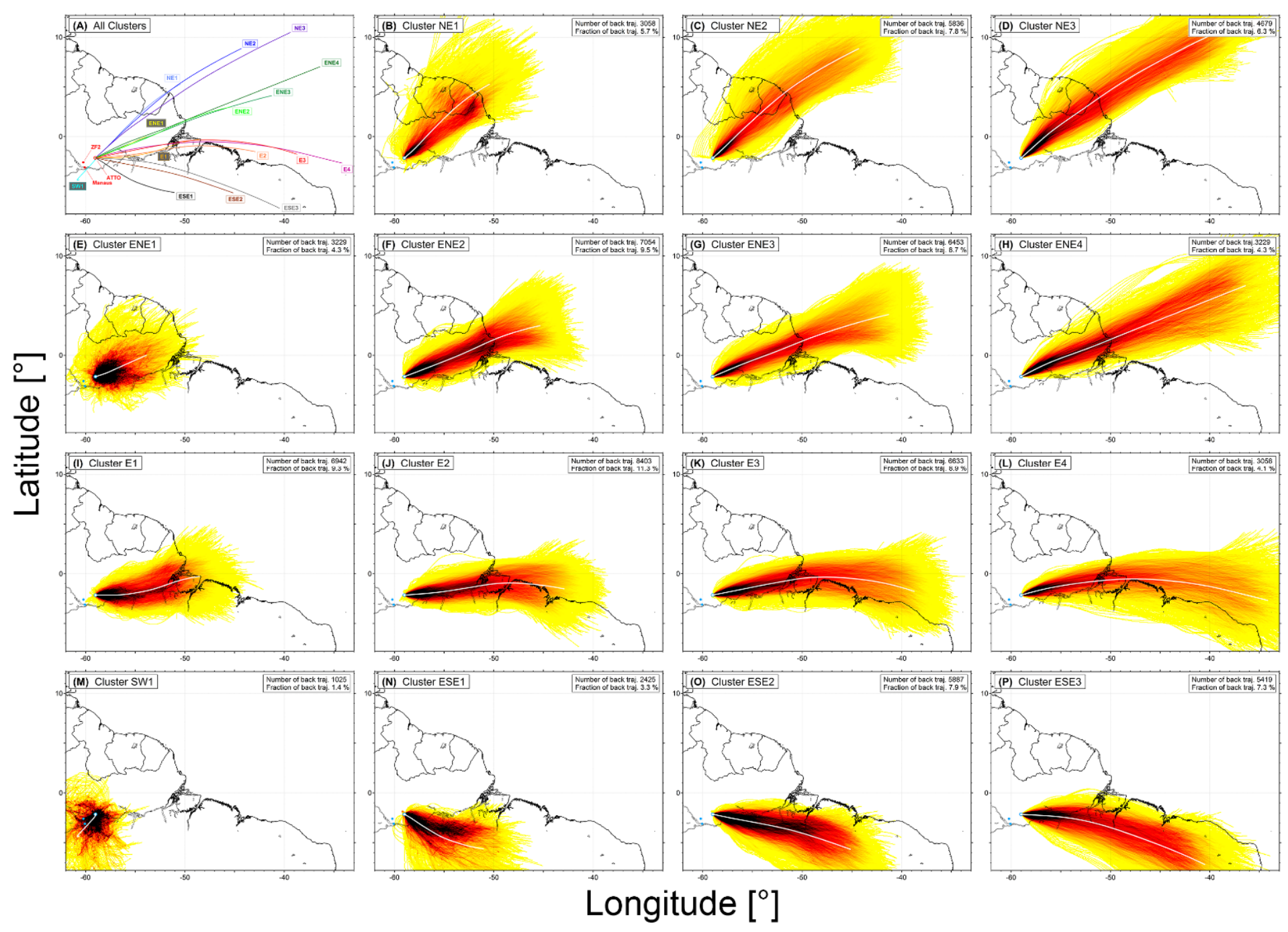

Figure S11. HYSPLIT back trajectory (BT) ensembles of the 15 clusters from the $k$-means cluster analysis (see Fig. 4). Individual maps show the average BT tracks (white lines) and the ensembles of all individual trajectories belonging to the respective clusters. The color code represents the average air mass residence time maps. The numbers $f$ and $N$ in the upper right corner of the individual panels specify for every cluster its relative fraction within the entire BT ensemble (74 496 individual BTs) as well as the absolute number of BTs included. 


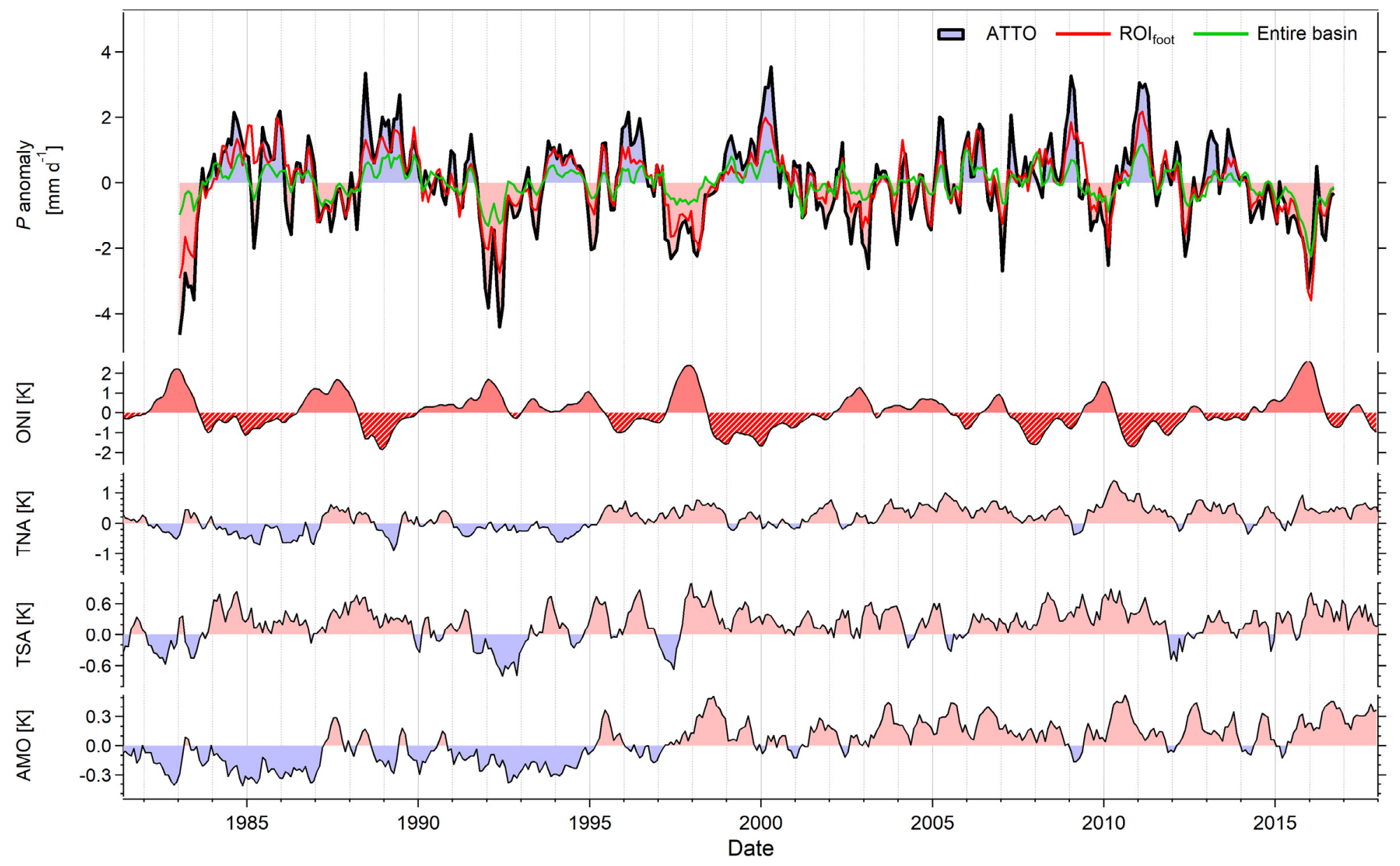

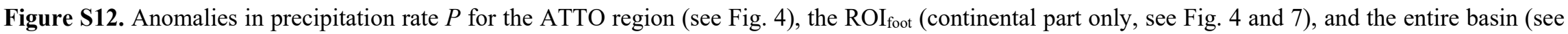
Amazon watershed region in Fig. 7). Pacific and Atlantic sea surface temperature indices are shown for comparison: Oceanic Niño index (ONI), representing Pacific SST variability and indicating El Niño vs. La Niña periods (i.e., El Niño influence is very strong for ONI $>2.0$, strong for $2.0>$ ONI $>1.5$, medium for $1.5>\mathrm{ONI}>1.0$, and weak for ONI $>1.0$. La Niña influence is strong for $-2.0<\mathrm{ONI}<-1.5$, medium for $-1.5<\mathrm{ONI}<-1.0$, and weak for ONI $>-1.0$.). Tropical Northern Atlantic (TNA) and tropical Southern Atlantic (TSA) indices, representing Atlantic SST variability. Atlantic Multidecadal Oscillation (AMO) index. 


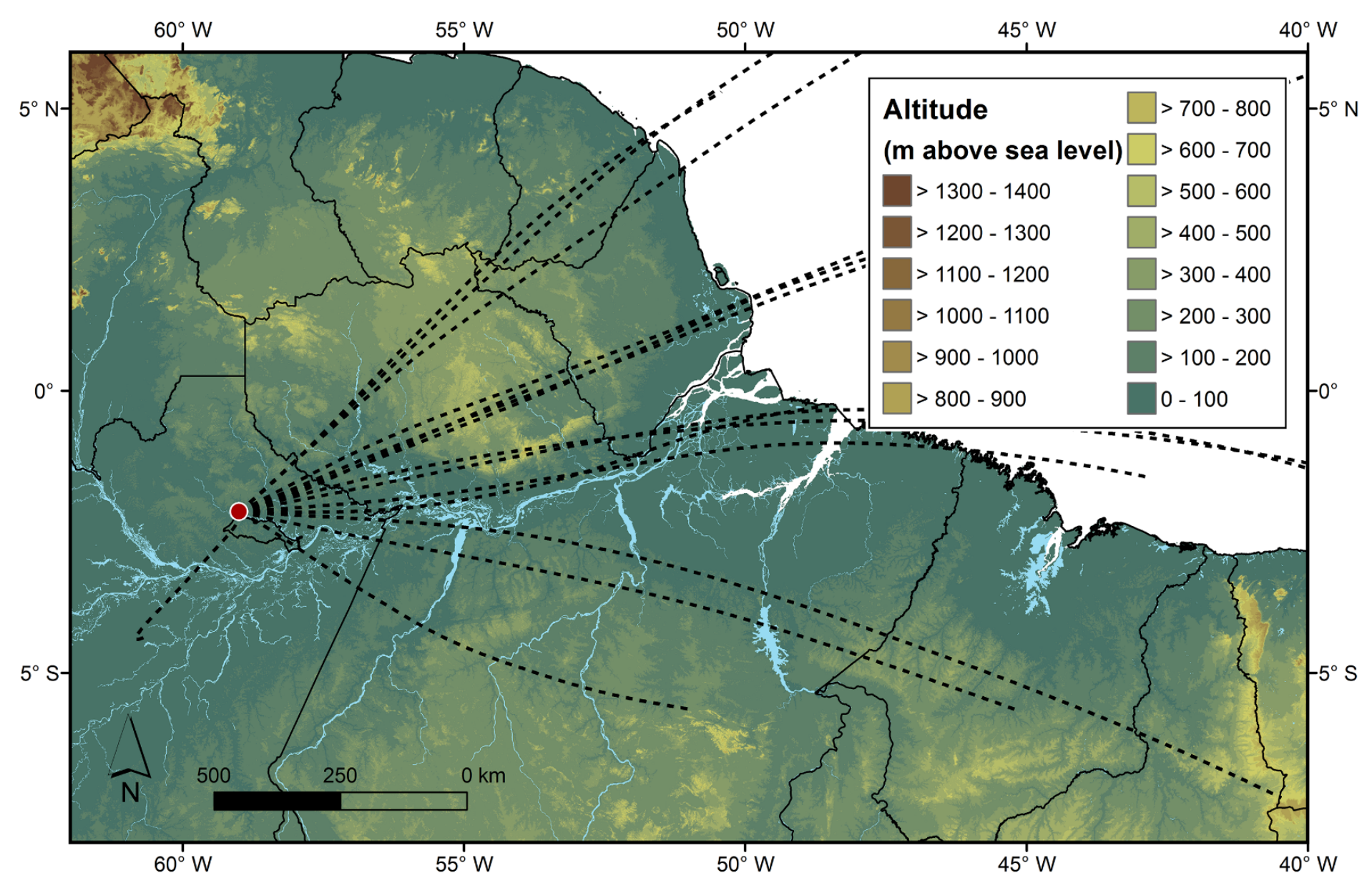

Figure S13. Map of the ATTO-relevant eastern Amazon Basin $\left(\mathrm{ROI}_{\mathrm{foot}}\right)$ combining the backward trajectory (BT) data with altitude data obtained from SRTM digital elevation model. The trajectory data is represented as center lines of the 15 BT clusters (black dashed lines, see Fig. 4). 

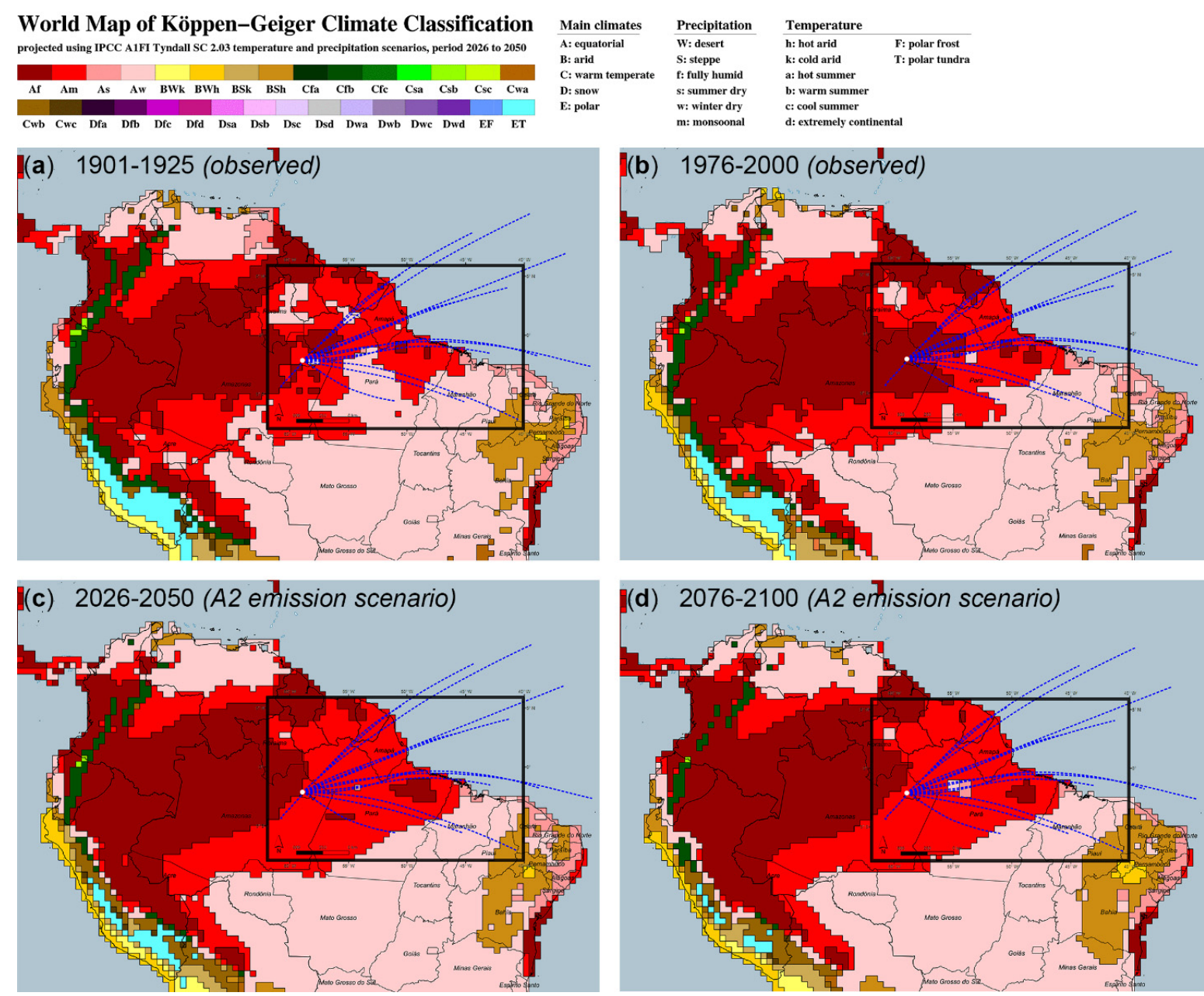

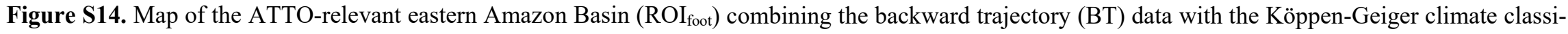
fication for two observed periods ( $\mathbf{a}$ and $\mathbf{b}$ ), and projected based on the IPCC A2 emission scenario (c and $\mathbf{d}$ ). The BT data is represented as center lines of the 15 BT clusters (blue dashed lines, see Fig. 4). 


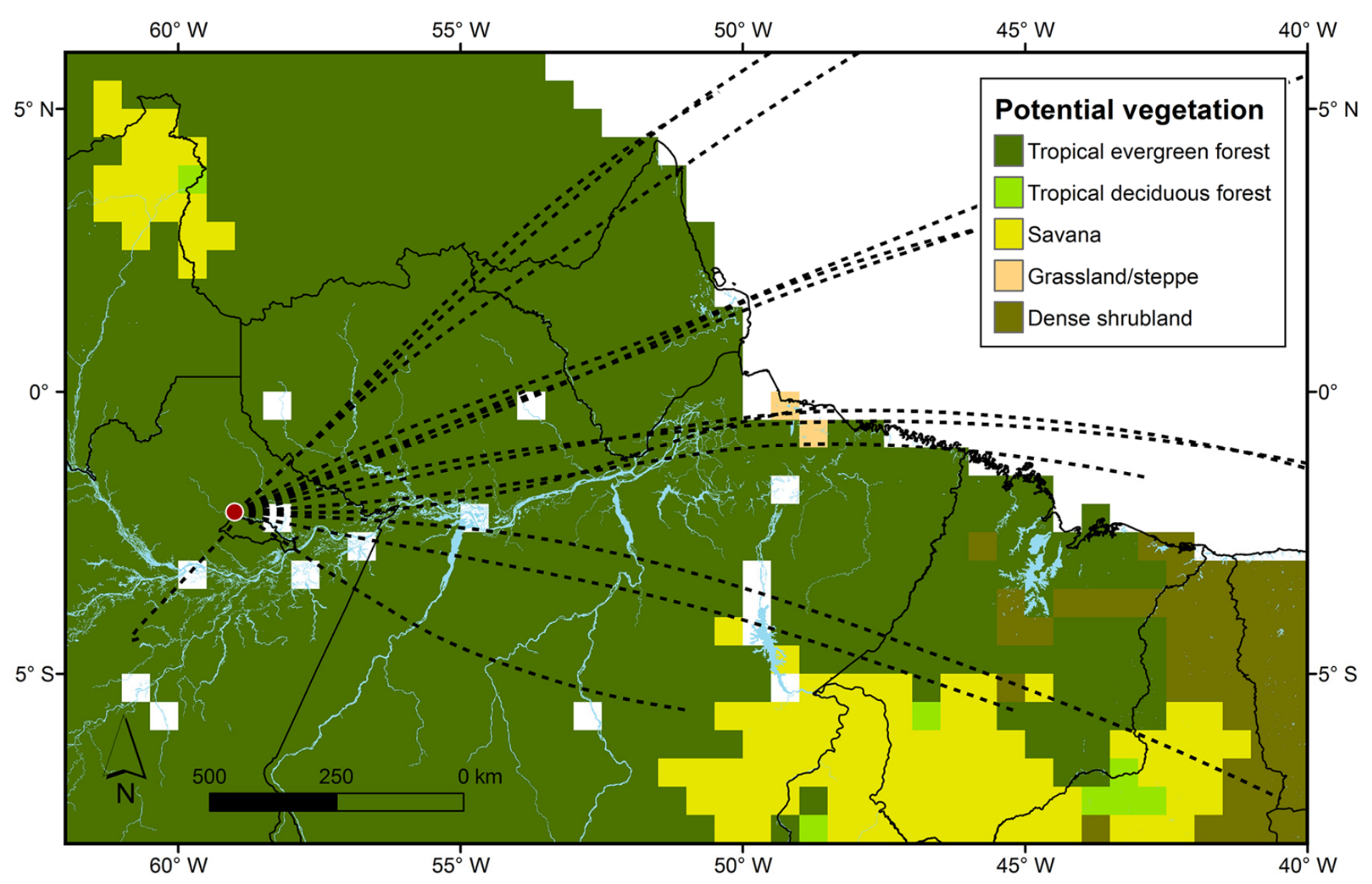

Figure S15. Map of the ATTO-relevant eastern Amazon Basin $\left(\mathrm{ROI}_{\mathrm{foot}}\right)$ combining the backward trajectory (BT) data with GIS data representing potential nature vegetation coverage in the absence of human alteration, according to (Ramankutty and Foley., 2010). The BT data is represented as center lines of the 15 BT clusters (black dashed lines, see Fig. 4). 


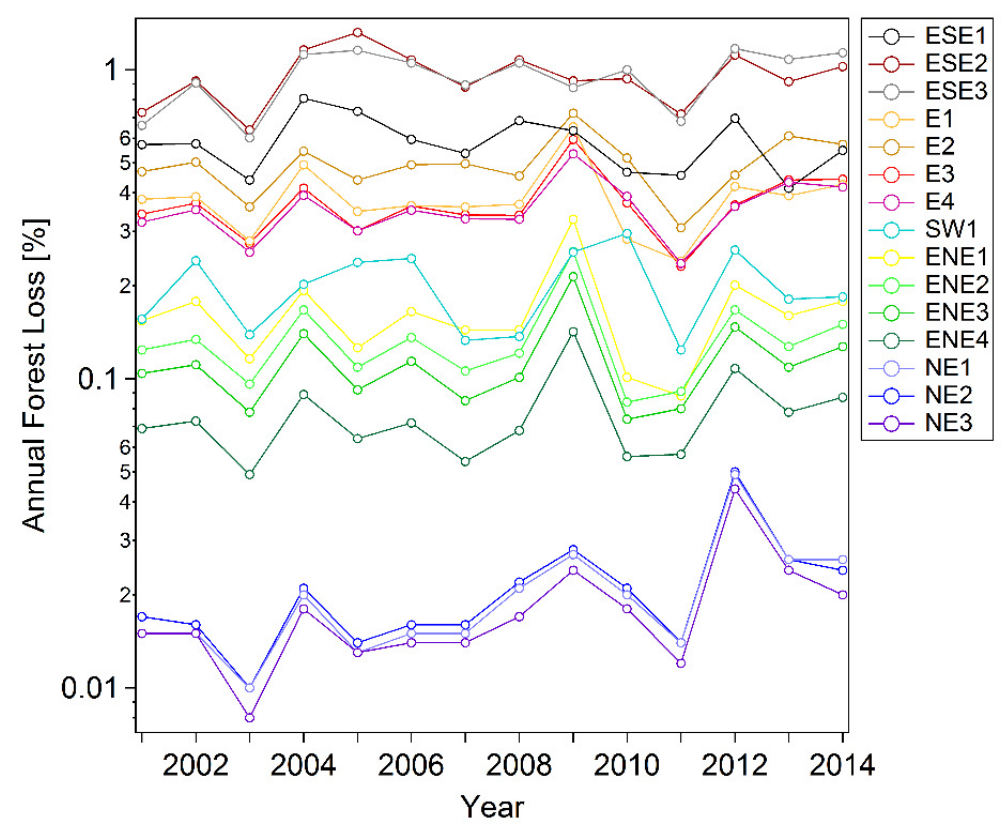

Figure S16. Quantitative characterization of forest loss trends (compare Fig. 13 and 14) in cluster BT footprints for all 15 clusters (see Fig. 4). The annual forest loss has been calculated relative to the forest cover in the year 2000. The forest loss data in the cluster BT footprints has been weighted by the air mass residence time. 


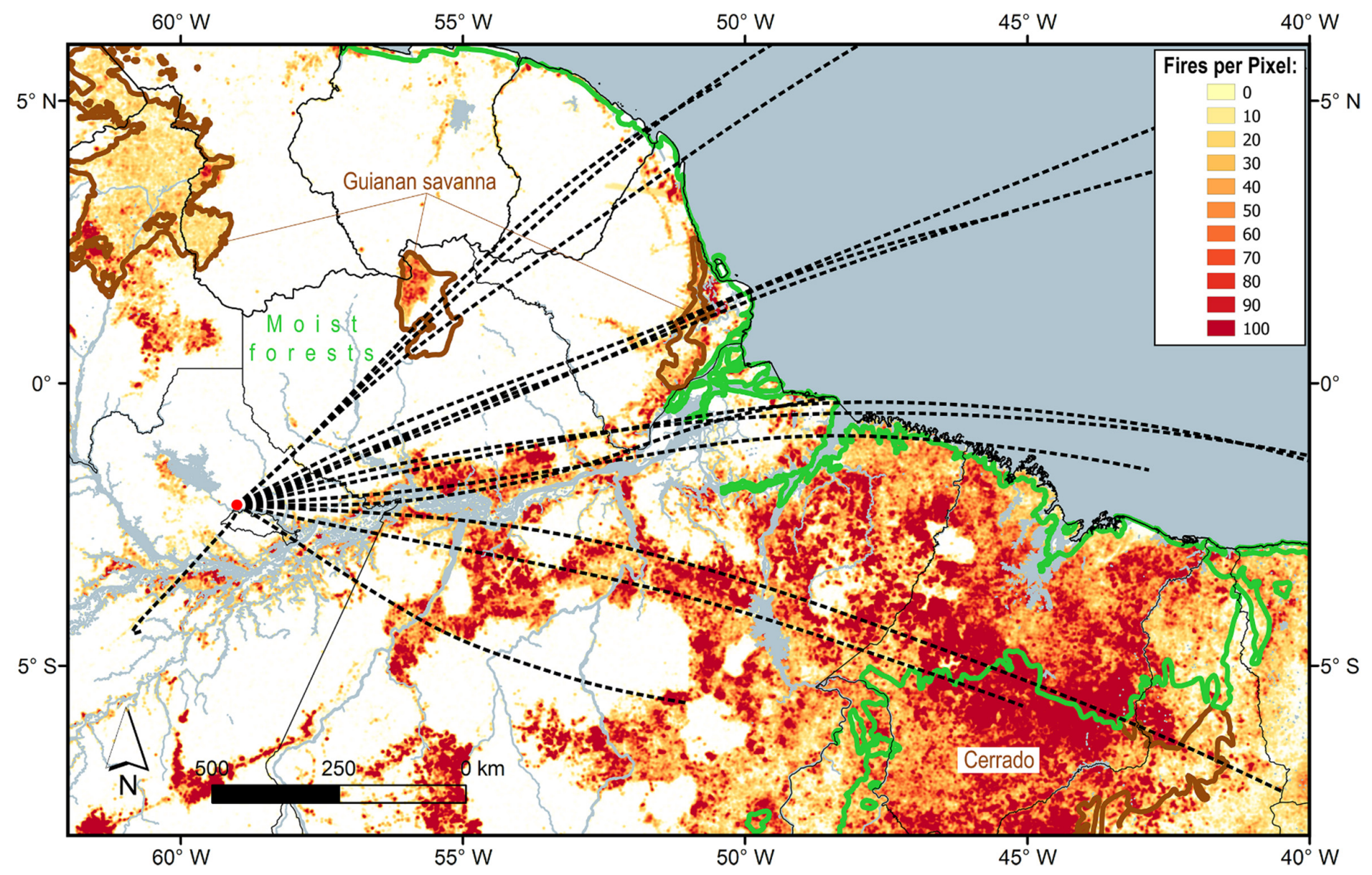

Figure S17. Map of the ATTO-relevant eastern Amazon Basin $\left(\mathrm{ROI}_{\text {foot }}\right)$ combining the backward trajectory (BT) data with two GIS data layer: (i) map of satellite detected fires within time period from 1998 to 2016 based on INPE data base and (ii) biome classification (see Fig. 9a). The BT data is represented as center lines of the 15 BT clusters (black dashed lines, see Fig. 4). 
(a) NE clusters

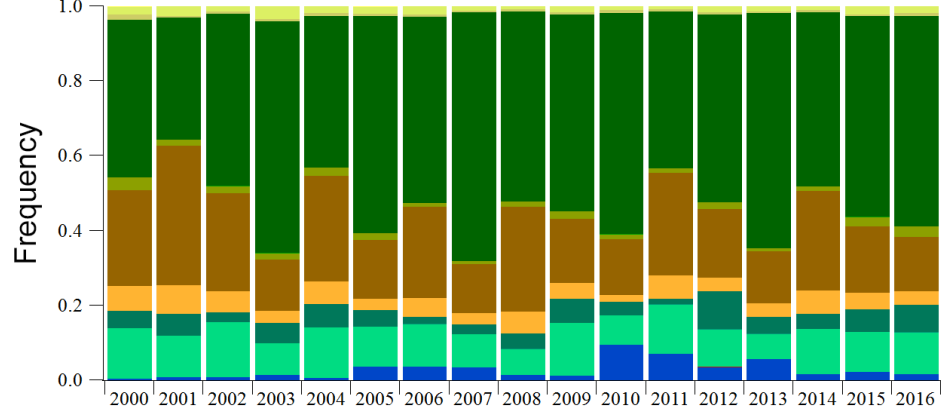

(b) ENE cluster

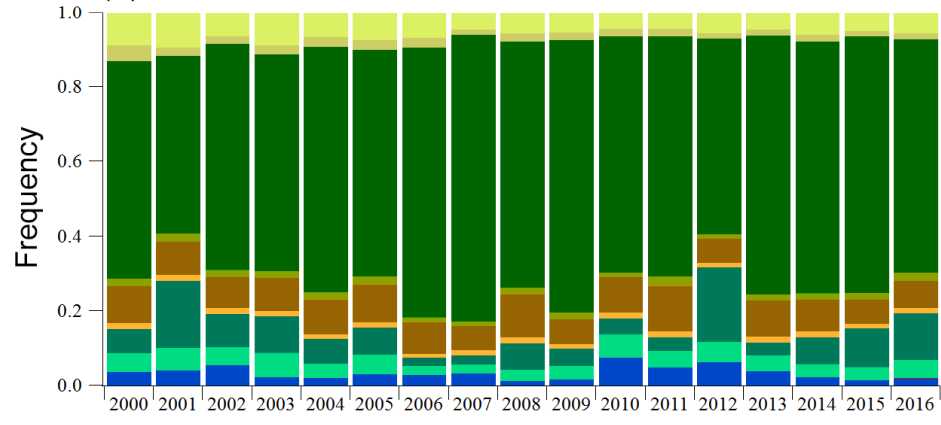

(C) E clusters

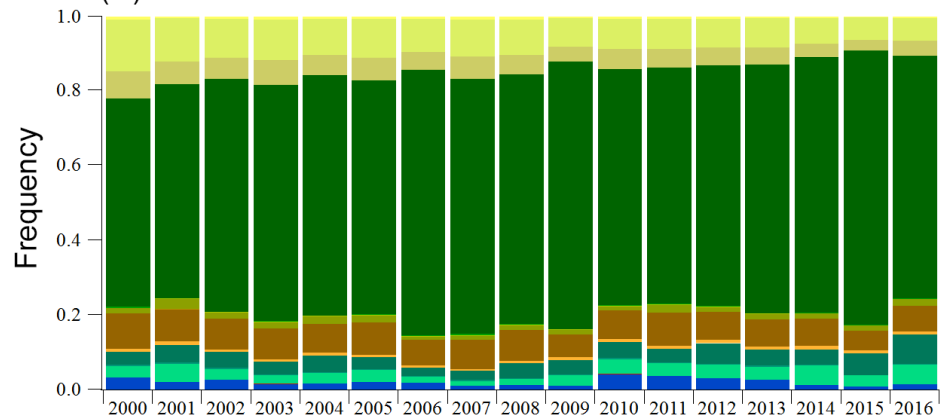

(d) ESE clusters
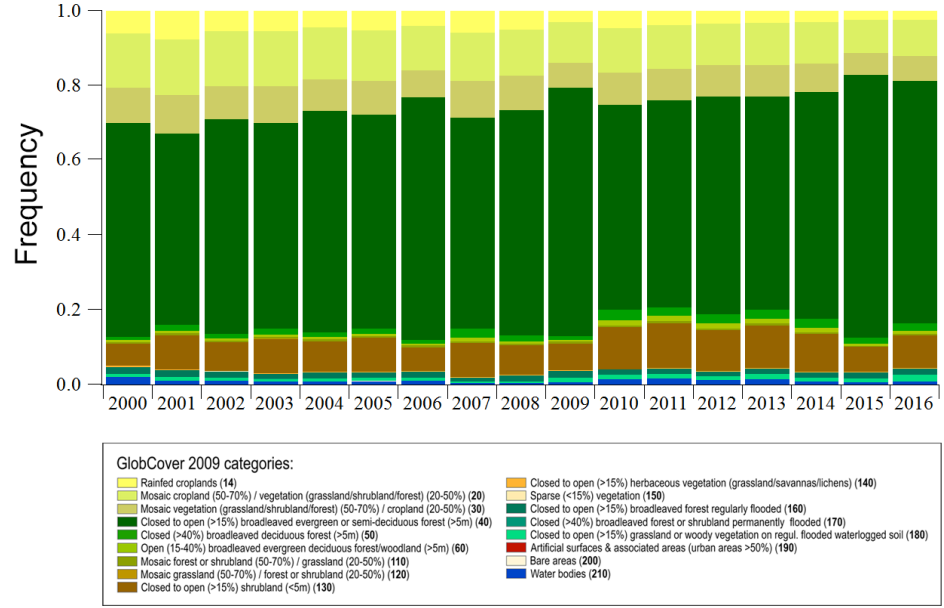

Figure S18. Relative fractions of ATTO-relevant fires (weighted with air mass residence times) within the different land cover categories, discriminated by major BT directions: NE, ENE, E, ESE, and SW. Fire analysis is based on the INPE database (see Sect. S1.1). Results shown here are averages of corresponding yearto-year data (2000-2016) as shown in Fig. S17. Results shown are temporally resolved on yearly basis. 


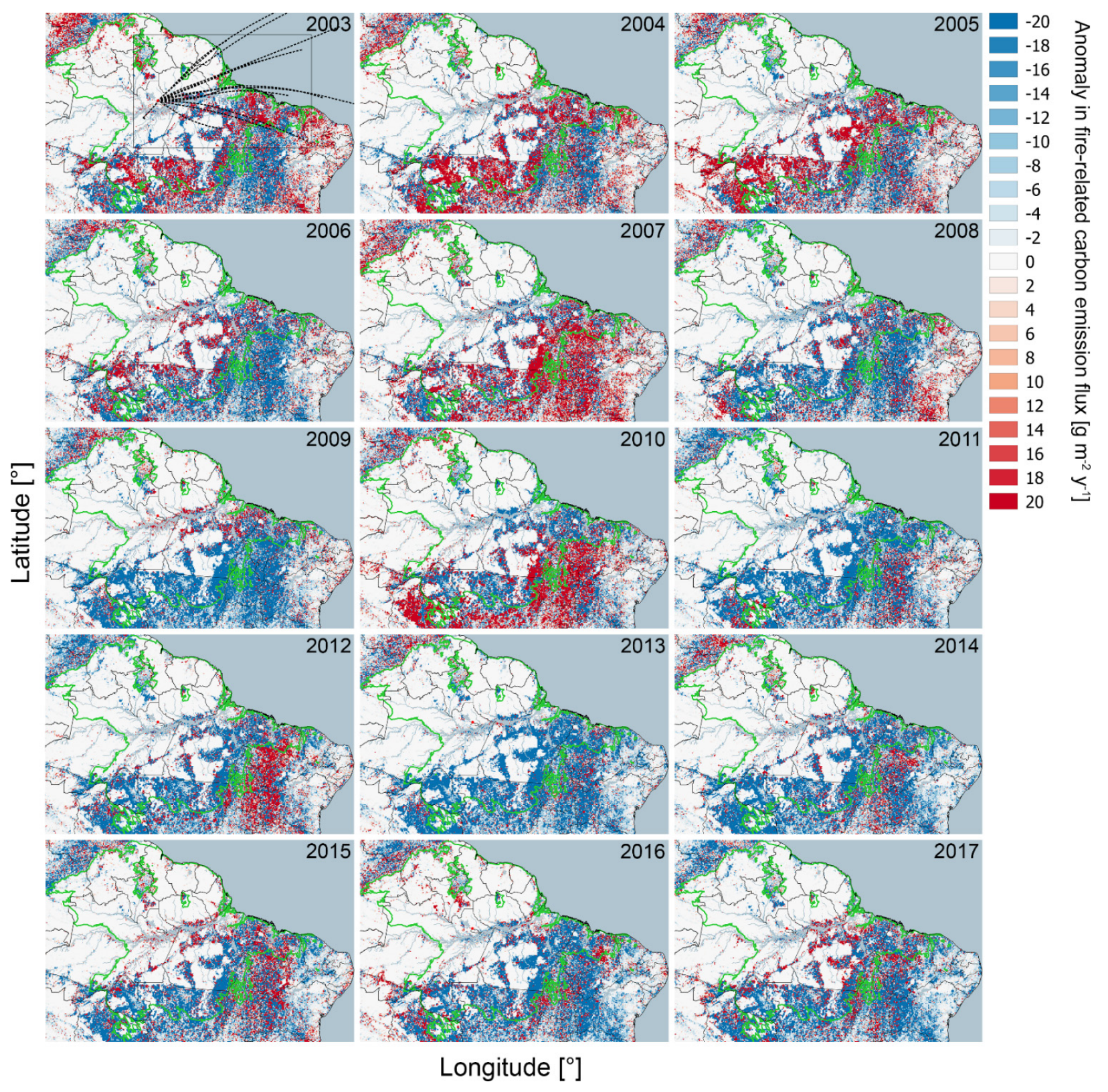

Figure S19. Anomalies in fire-related carbon emission based on GFAS-data for the ATTO-relevant eastern Amazon Basin $\left(\mathrm{ROI}_{\mathrm{foot}}\right)$. Reference time period for anomalies is average from 2003 to 2017. For the year 2003, the BT data is represented as center lines of the 15 BT cluster (black dashed lines, exemplary for year 2003, see Fig. 4). The green line represents the boundaries of the biome of moist broadleaf forests according to Fig. 9. 

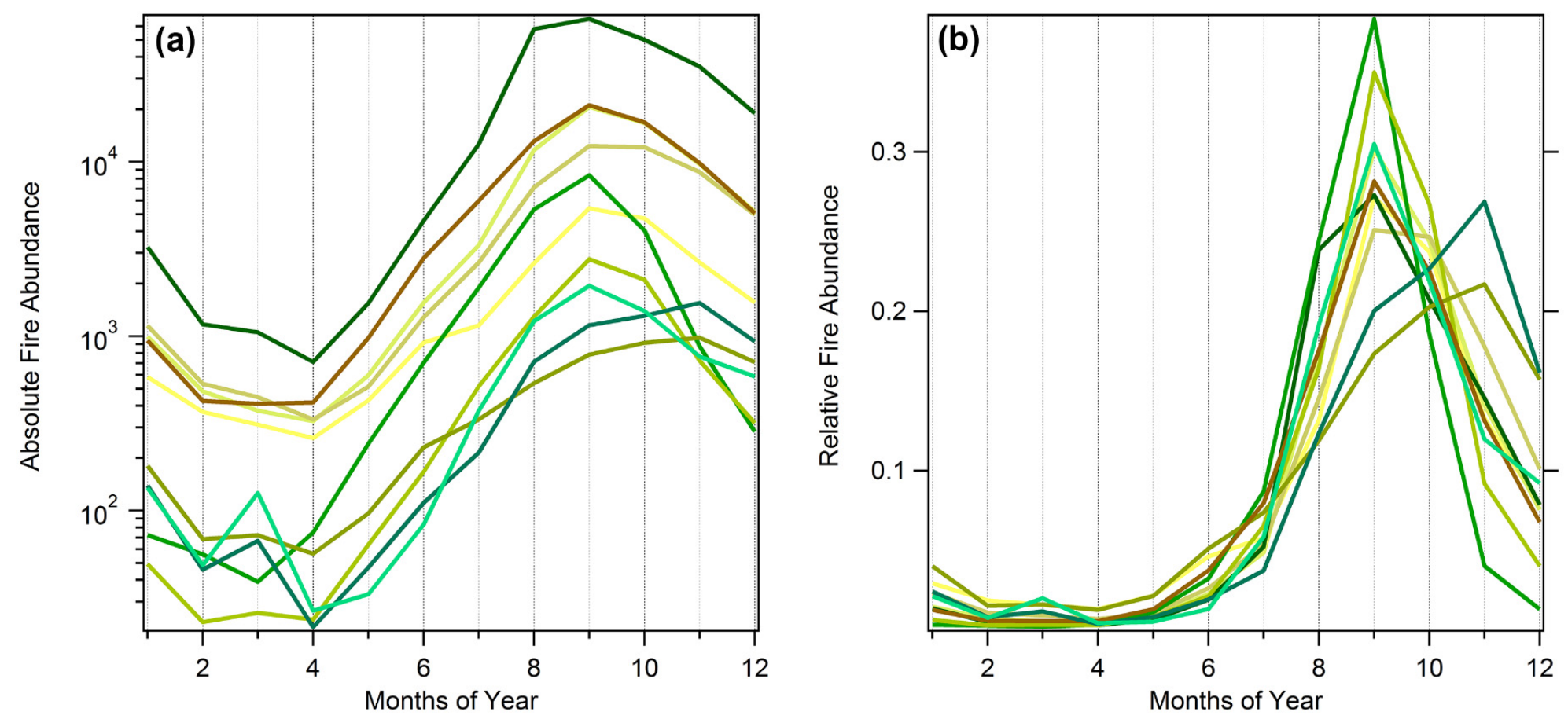

Figure S20. Seasonal cycle of satellite-detected fire activity (INPE data set), categorized by land cover type, in which they are detected. This analysis includes all fires in the ATTO site footprint (represented by the combination of all BT cluster footprints). The fire count was weighted by the BT density and, thus, reflects the distance and relevance of the individual fires for the ATTO site. (a) Absolute fire count emphasizes in which land cover category fires are most abundant. (b) Normalized seasonal cycles in fire activity, shows a fire maximum in Sep and minimum in Apr. The legend of the GlobCover 2009 color code is shown in Fig. 9. 


\section{References}

Arino, O., Bicheron, P., Achard, F., Latham, J., Witt, R., and Weber, J.-L.: GLOBCOVER The most detailed portrait of Earth, Esa Bulletin-European Space Agency, 24-31, 2008.

Asefi-Najafabady, S., Rayner, P. J., Gurney, K. R., McRobert, A., Song, Y., Coltin, K., Huang, J., Elvidge, C., and Baugh, K.: A multiyear, global gridded fossil fuel $\mathrm{CO} 2$ emission data product: Evaluation and analysis of results, Journal of Geophysical Research-Atmospheres, 119, 10.1002/2013jd021296, 2014.

Congalton, R. G., Gu, J. Y., Yadav, K., Thenkabail, P., and Ozdogan, M.: Global Land Cover Mapping: A Review and Uncertainty Analysis, Remote Sensing, 6, 12070-12093, 10.3390/rs61212070, 2014.

Defourny, P., Schouten, L., Bartalev, S., Bontemps, S., Caccetta, P., De Wit, A. J. W., Di Bella, C. M., Gérard, B., Giri, P., Gond, V., ., and et al.: Accuracy assessment of a $300 \mathrm{~m}$ global land cover map : the GlobCover experience, International Symposium on Remote sensing of Environment, Stresa, Italie, 2009-05-04 / 2009-05-08, Agritrop : 552799, 2009.

Farr, T. G., Rosen, P. A., Caro, E., Crippen, R., Duren, R., Hensley, S., Kobrick, M., Paller, M., Rodriguez, E., Roth, L., Seal, D., Shaffer, S., Shimada, J., Umland, J., Werner, M., Oskin, M., Burbank, D., and Alsdorf, D.: The shuttle radar topography mission, Rev. Geophys., 45, 33, 10.1029/2005rg000183, 2007.

Hansen, M. C., Potapov, P. V., Moore, R., Hancher, M., Turubanova, S. A., Tyukavina, A., Thau, D., Stehman, S. V., Goetz, S. J., Loveland, T. R., Kommareddy, A., Egorov, A., Chini, L., Justice, C. O., and Townshend, J. R. G.: High-Resolution Global Maps of 21st-Century Forest Cover Change, Science, 342, 850-853, 10.1126/science.1244693, 2013.

Hijmans, R. J., Cameron, S. E., Parra, J. L., Jones, P. G., and Jarvis, A.: Very high resolution interpolated climate surfaces for global land areas, International Journal of Climatology, 25, 1965-1978, 10.1002/joc.1276, 2005.

Hutchinson, M. F.: Anusplin Version 4.3., in, The Australian National University, Canberra, Australia, Centre for Resource and Environmental Studies, 2004.

Kaiser, J. W., Heil, A., Andreae, M. O., Benedetti, A., Chubarova, N., Jones, L., Morcrette, J. J., Razinger, M., Schultz, M. G., Suttie, M., and van der Werf, G. R.: Biomass burning emissions estimated with a global fire assimilation system based on observed fire radiative power, Biogeosciences, 9, 527554, 10.5194/bg-9-527-2012, 2012.

Kottek, M., Grieser, J., Beck, C., Rudolf, B., and Rubel, F.: World map of the Koppen-Geiger climate classification updated, Meteorologische Zeitschrift, 15, 259-263, 10.1127/0941-2948/2006/0130, 2006.

Lehner, B., Liermann, C. R., Revenga, C., Vorosmarty, C., Fekete, B., Crouzet, P., Doll, P., Endejan, M., Frenken, K., Magome, J., Nilsson, C., Robertson, J. C., Rodel, R., Sindorf, N., and Wisser, D.: High-resolution mapping of the world's reservoirs and dams for sustainable river-flow management, Frontiers in Ecology and the Environment, 9, 494-502, 10.1890/100125, 2011.

Olson, D. M., Dinerstein, E., Wikramanayake, E. D., Burgess, N. D., Powell, G. V. N., Underwood, E. C., D'amico, J. A., Itoua, I., Strand, H. E., Morrison, J. C., Loucks, C. J., Allnutt, T. F., Ricketts, T. H., Kura, Y., Lamoreux, J. F., Wettengel, W. W., Hedao, P., and Kassem, K. R.: Terrestrial Ecoregions of the World: A New Map of Life on Earth, Bioscience, 51, 933-938, 10.1641/00063568(2001)051[0933:teotwa]2.0.co;2, 2001.

Paruelo, J. M., Jobbagy, E. G., and Sala, O. E.: Current distribution of ecosystem functional types in temperate South America, Ecosystems, 4, 683-698, 10.1007/s10021-001-0037-9, 2001.

Quaife, T., and Cripps, E.: Bayesian Analysis of Uncertainty in the GlobCover 2009 Land Cover Product at Climate Model Grid Scale, Remote Sensing, 8, 18, 10.3390/rs8040314, 2016. 
Ramankutty, N., and Foley, J. A.: ISLSCP II Potential Natural Vegetation Cover. In Hall, Forest G., G. Collatz, B. Meeson, S. Los, E. Brown de Colstoun, and D. Landis (eds.). ISLSCP Initiative II Collection. Data set. Available on-line [http://daac.ornl.gov/] from Oak Ridge National Laboratory Distributed Active Archive Center, Oak Ridge, Tennessee, U.S.A. doi:10.3334/ORNLDAAC/961, in, 2010.

Rayner, P. J., Raupach, M. R., Paget, M., Peylin, P., and Koffi, E.: A new global gridded data set of $\mathrm{CO} 2$ emissions from fossil fuel combustion: Methodology and evaluation, Journal of Geophysical Research-Atmospheres, 115, 10.1029/2009jd013439, 2010.

Rouse, J. W., Haas, R. H., Schell, J. A., and Deering, D. W.: Monitoring vegetation systems in the Great Plains with ERTS. Third ERTS Symposium 1, 309-317, 1973.

Rubel, F., and Kottek, M.: Observed and projected climate shifts 1901-2100 depicted by world maps of the Koppen-Geiger climate classification, Meteorologische Zeitschrift, 19, 135-141, 10.1127/09412948/2010/0430, 2010.

Sanderson, E. W., Jaiteh, M., Levy, M. A., Redford, K. H., Wannebo, A. V., and Woolmer, G.: The human footprint and the last of the wild, Bioscience, 52, 891-904, 10.1641/00063568(2002)052[0891:thfatl]2.0.co;2, 2002.

Saturno, J., Holanda, B. A., Pöhlker, C., Ditas, F., Wang, Q., Moran-Zuloaga, D., Brito, J., Carbone, S., Cheng, Y., Chi, X., Ditas, J., Hoffmann, T., Hrabe de Angelis, I., Könemann, T., Lavrič, J. V., Ma, N., Ming, J., Paulsen, H., Pöhlker, M. L., Rizzo, L. V., Schlag, P., Su, H., Walter, D., Wolff, S., Zhang, Y., Artaxo, P., Pöschl, U., and Andreae, M. O.: Black and brown carbon over central Amazonia: Longterm aerosol measurements at the ATTO site, Atmos. Chem. Phys. Discuss., 2017, 1-57, 10.5194/acp2017-1097, 2017.

Soares-Filho, B. S., Nepstad, D. C., Curran, L. M., Cerqueira, G. C., Garcia, R. A., Ramos, C. A., Voll, E., McDonald, A., Lefebvre, P., and Schlesinger, P.: Modelling conservation in the Amazon basin, Nature, 440, 520-523, 10.1038/nature04389, 2006.

Soares-Filho, B. S., Nepstad, D. C., Curran, L. M., Voll, E., Cerqueira, G. C., Garcia, R. A., Ramos, C. A., McDonald, A., Lefebvre, P., and Schlesinger, P.: Modeled Deforestation Scenarios, Amazon Basin: 2002-2050., in, edited by: Oak Ridge National Laboratory Distributed Active Archive Center, O. R., Tennessee, USA, 2013.

Souza, C. M., Siqueira, J. V., Sales, M. H., Fonseca, A. V., Ribeiro, J. G., Numata, I., Cochrane, M. A., Barber, C. P., Roberts, D. A., and Barlow, J.: Ten-Year Landsat Classification of Deforestation and Forest Degradation in the Brazilian Amazon, Remote Sensing, 5, 5493-5513, 10.3390/rs5115493, 2013.

Tyukavina, A., Hansen, M. C., Potapov, P. V., Stehman, S. V., Smith-Rodriguez, K., Okpa, C., and Aguilar, R.: Types and rates of forest disturbance in Brazilian Legal Amazon, 2000-2013, Science Advances, 3, 15, 10.1126/sciadv.1601047, 2017.

Weiss, D. J., Nelson, A., Gibson, H. S., Temperley, W., Peedell, S., Lieber, A., Hancher, M., Poyart, E., Belchior, S., Fullman, N., Mappin, B., Dalrymple, U., Rozier, J., Lucas, T. C. D., Howes, R. E., Tusting, L. S., Kang, S. Y., Cameron, E., Bisanzio, D., Battle, K. E., Bhatt, S., and Gething, P. W.: A global map of travel time to cities to assess inequalities in accessibility in 2015, Nature, 553, 333-+, 10.1038/nature25181, 2018. 